\title{
Cleft Rhinoplasty
}

\author{
Sunil Richardson and Rakshit Vijay Sinai Khandeparker
}

\subsection{Introduction}

Rhinoplasties in cleft lip and palate (CLP) patients are considered one of the most difficult and challenging surgeries to carry out. The reasons understood for this are twofold: the principal reason being the simultaneous involvement of all the layers of the nose, including the skin, cartilage, skeleton and vestibular lining, and the other the significant scarring that accompanies multiple previous surgical interventions. The deformity has a major impact on nasal aesthetics as well as function and can range from being absolutely inconspicuous to catastrophic.

The literature is flooded with numerous techniques for ultimate correction of unilateral and bilateral cleft lip-nasal deformities. More recently, most cleft surgeons have started opting for primary rhinoplasties at the time of lip repair with or without presurgical orthopaedics. These early interventions have definitely improved the nasal deformity and the overall nasal symmetry; however, definitive rhinoplasty may still be required at a later date as the child grows. Despite all the recent developments in cleft surgery, an optimal surgical modality that addresses the issues of desired nasal form coupled with long-term stability for correction of cleft lip-nasal deformity still fails to exist.

Disclosure: Authors have no financial conflicts to disclose

Electronic Supplementary Material The online version of this chapter (https://doi.org/10.1007/978-981-15-1346-6_76) contains supplementary material, which is available to authorized users.

S. Richardson $(\square)$

Richardson's Dental and Craniofacial Hospital,

Chunkan Kadai, Nagercoil, Tamil Nadu, India

R. V. S. Khandeparker

Department of Oral and Maxillofacial Surgery, Goa Dental College

and Hospital, Bambolim, Goa, India

\subsection{Pathologic Anatomy}

A clear understanding of the associated complex anatomical and pathological abnormalities is paramount to obtaining desired nasal form and function [1].

\subsubsection{Unilateral Cleft Nasal Deformity}

The hallmark of unilateral cleft nasal deformity is a threedimensional asymmetry of the nasal tip and the alar base (Fig. 76.1a-c). The characteristic features include:

1. Asymmetric nasal tip: This is principally due to a shorter medial crus and longer lateral crus of the lower lateral cartilage (LLC) on the cleft side as compared to the non-cleft side. This contributes to a poorly defined nasal tip with less projection [2]. Furthermore, the angle between the medial and lateral crura on the cleft side is increased.

2. Alar dome is flat and wider on the cleft side due to posterolateral displacement of the alar dome [2].

3. Deviation of the columellar base to the non-cleft side: The unilateral cleft results in a discontinuous insertion of the orbicularis oris muscle into the columellar base on the non-cleft side rather than a horizontal insertion and continuous decussation as seen in the normal lip. The contraction of the orbicularis oris muscle results in an unopposed pull of the columella, caudal septum and premaxilla to the non-cleft side [3].

4. Alar base on the cleft side is directed laterally, posteriorly and inferiorly: Two factors contribute to this: one being the insertion of the orbicularis oris into the alar base and the other the deficient maxillary skeletal framework at the alar base [3].

5. Hypoplastic maxilla on the cleft side.

6. Wide and horizontally directed nostril on the cleft side: This is brought about by a combination of vector of 

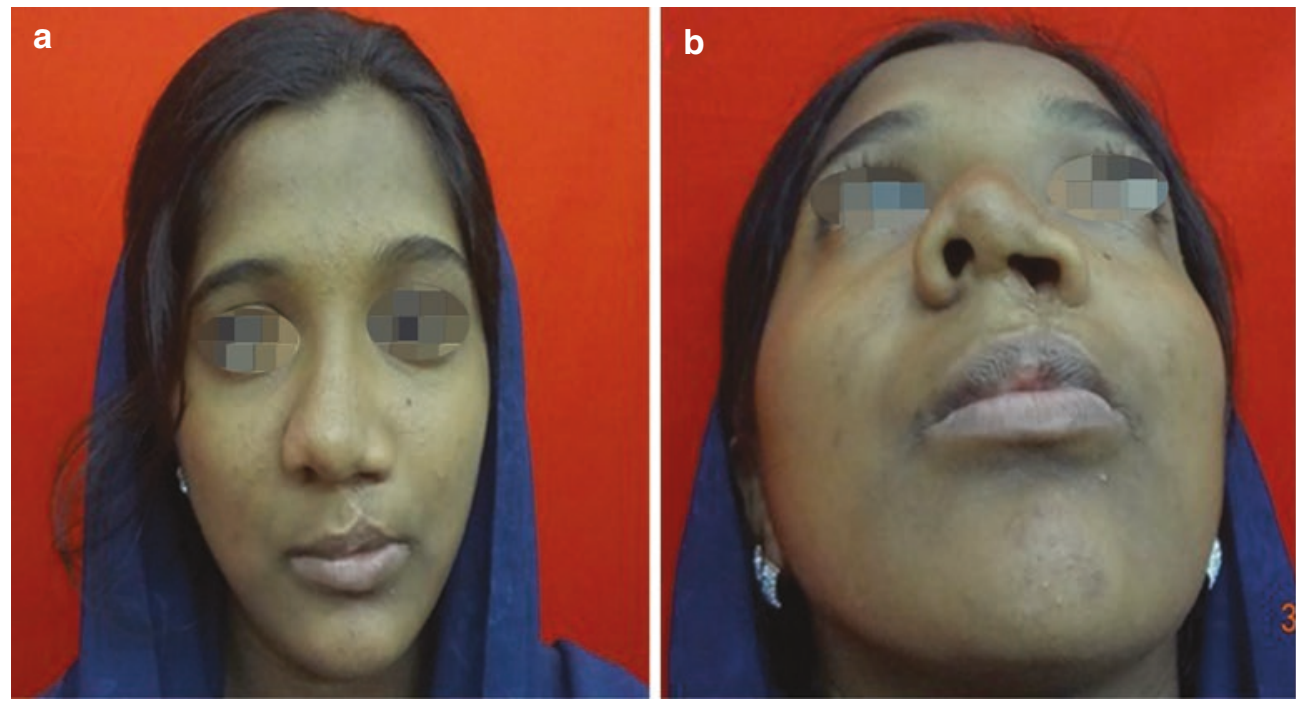

C

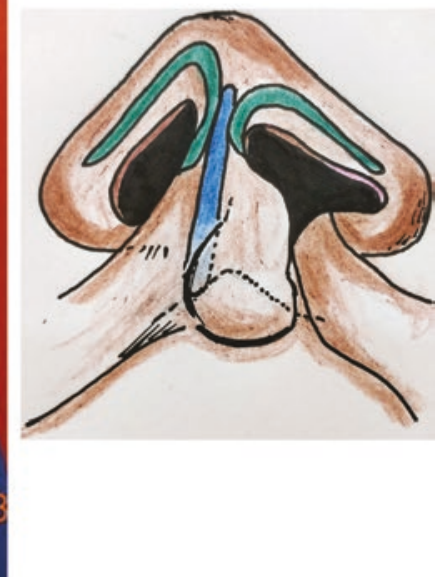

CAssociation of Oral and Maxillofacial Surgeons of India

Fig. 76.1 (a-c) Photographs depicting the pathologic anatomy as observed in unilateral cleft nasal deformity. (a) Frontal view showing the deviation of the nasal root towards the non-cleft side with asymmetrical appearing nasal tip. (b) Basal view depicting the deviation of the base of the columella to the non-cleft side. Also, observe the wide and horizontally directed nostril on the cleft side. Furthermore, the alar base on the cleft side is directed laterally, posteriorly and inferiorly. (c) Pictorial depiction of deviation of the caudal nasal septum (blue) towards the non-cleft side orbicularis oris muscle pull and asymmetric LLC on the cleft side $[4,5]$.

7. Deviation of the caudal septum to the non-cleft side: The unopposed pull of the orbicularis oris muscle due to its improper insertion into the columellar base results in deviation of the caudal septum to the non-cleft side [3]. This force affects only the caudal septum and results in deflection of the cartilaginous and bony septum into the cleft side posteriorly. This alone or in association with hypertrophied nasal turbinates significantly narrows the opening of the nasal airway and contributes to nasal airway obstruction [6].

8. Compromised external nasal valve: This is the consequence of two related factors: introversion of the nasal ala and webbing of the nasal vestibule. Due to the position of the columella and alar base on the cleft side, the LLC is subjected to distortional forces that causes it to rotate posteroinferiorly and brings about introversion of the cleft side nasal ala [7]. This leads to hooding and thickening of the ala and together with surgical scarring forms an oblique fold and contributes to webbing of the nasal vestibule. This tissue bulk has an influence on the nasal airflow and significantly alters the relationship of upper lateral cartilages (ULCs) and LLCs.

9. Weakened upper lateral cartilages (ULC) and abnormal relationship to LLCs: On the cleft side, the ULC displays side-to-side relationship rather than the typical overlap type of relationship seen on the non-cleft side. The ULC on the cleft side is also weakened by inadequate skeletal support [8]. The consequence of both these factors is reduced support and collapse of the ULC with deep inspiration.

10. Compromised internal nasal valve on the cleft side: This is primarily because of septal bowing into the cleft side at the internal nasal valve together with weakened support of the ULC at the cleft side which causes the cartilage to collapse with respiration.

\subsubsection{Bilateral Cleft Nasal Deformity}

The bilateral cleft lip nasal deformity is grossly symmetrical and shares similar clinical characteristics as observed in unilateral cleft deformity [9, 10] (Fig. 76.2a-c). The clinical characteristics include:

1. Under-projected and bifid nasal tip: The lateral crus of the LLC is long, and the medial crus is short which leads to under-projection of the nasal tip. The medial crura are typically splayed, producing a poorly defined, bifid tip [11]. The nose is wide and depressed.

2. Blunting of the alar dome with a more obtuse angle due to posterolateral displacement of the alar domes [11]. 

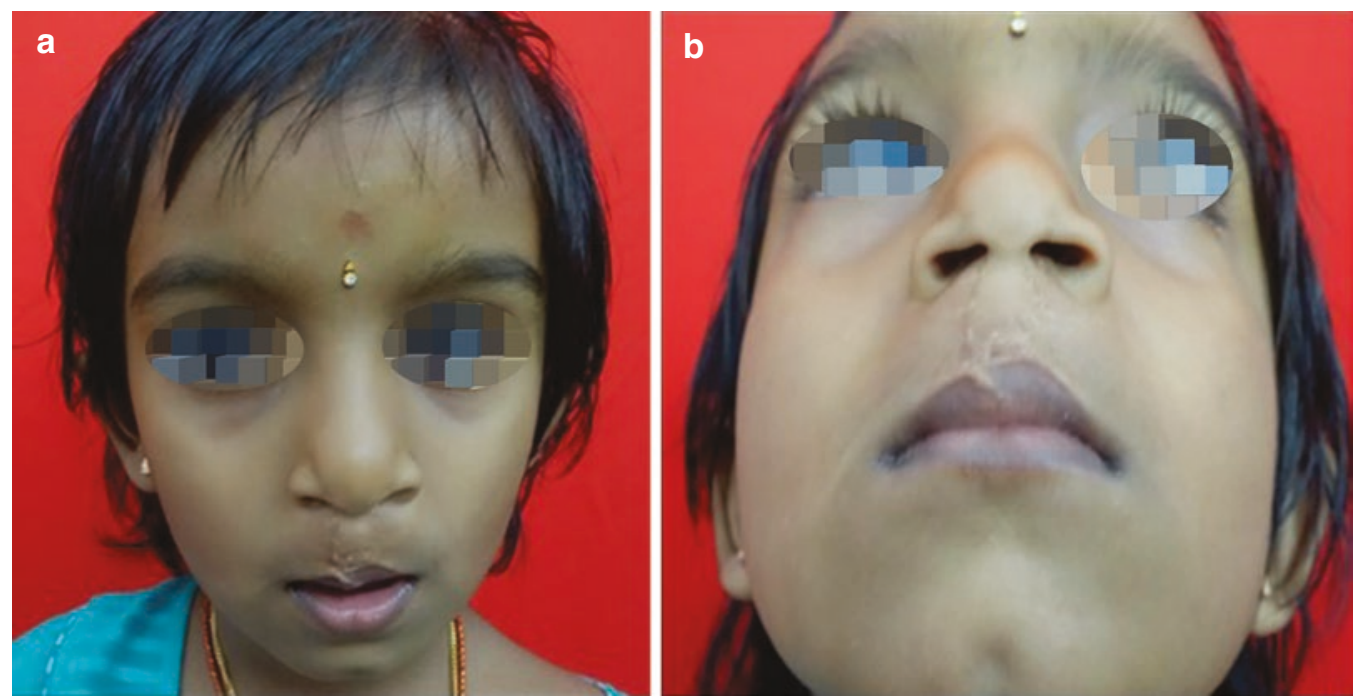

C

CAssociation of Oral and Maxillofacial Surgeons of India

Fig. 76.2 (a-c) Photographs depicting the pathologic anatomy as observed in bilateral cleft nasal deformity. (a) Frontal view demonstrating a more or less symmetrical deformity with bifid nasal tip and blunting of the alar dome. (b) Basal view depicting symmetrical position of the caudal nasal septum, short columella and bilateral displacement of the alar bases laterally, posteriorly and inferiorly with wide and horizontally directed nostrils bilaterally. (c) Pictorial depiction of the classical midline position of the caudal nasal septum
3. Short columella with a wider base: The columella is short or nearly absent as a consequence of decreased soft tissue and skin between the nasal tip and the upper lip [12].

4. Alar bases are displaced laterally, posteriorly and inferiorly. This brings about flaring of the alar bases and widening of the nostrils.

5. Hypoplastic maxillae bilaterally.

6. Nostrils are wide and horizontally directed with margins buckling inwards.

7. Classical midline positioning of the septum. The nasal septum is classically midline; however, in case of a slight discrepancy, the septum deviates to the less affected side [13, 14].

8. The external nasal valve is compromised by introversion of the LLCs and webbing of the nasal vestibules bilaterally.

9. The ULCs are weakened and display abnormal relationship to LLCs similar to that seen in the unilateral cleft nasal deformity.

10. The internal nasal valve is compromised by weakened support of the ULC: It is important to note that midline positioning of the nasal septum in bilateral cleft nasal deformity results in compromise of the internal nasal valve to a lesser significant degree as compared to the unilateral cleft nasal deformity.

\subsection{Surgical Timing}

The timing of cleft lip nasal repairs can be divided into primary, intermediate and secondary or definitive repairs.

\subsubsection{Primary Rhinoplasty}

Initially, most surgeons were sceptical with early nasal interventions at the time of cleft lip repair following demonstrations of impairment of nasal and midfacial growth in experimental studies that resulted after large submucosal resections of the nasal septum. However, studies by McComb and Coghlan [7] have dispelled this philosophy and demonstrated that early interventions seldom interfere with growth provided the lower lateral cartilage is only repositioned and not resected. Primary rhinoplasties are now increasingly accepted, and their positive effects on secondary rhinoplasties are well documented.

Primary cleft rhinoplasty is typically carried out at 3 months of age at the time of primary cheiloplasty [15]. An early intervention improves the existing cleft nasal deformity by achieving better symmetry, allowing the nose to grow in a symmetric fashion and potentially improving long-term appearance and the final outcome.

The definite goals of the procedure are highlighted in Box 76.1 . 


\section{Box 76.1: Definite Goals of Primary Cleft Rhinoplasty}

- To bring about approximation of the nasal floor to establish a muscle and soft tissue sill across the nasal base

- Symmetrical positioning of the abnormally positioned LLC

- Providing nasal tip support

- Repositioning of the alar base and correction of the webbed lateral alar mucosa by plicating skin and mucosa [16]
The addition of presurgical naso-alveolar moulding device is advocated by some authors in conjunction with primary surgery. The technique delivers continuous low-level pressure on the alveolar segments and is highly successful in shaping the nasal cartilage within the initial 6 weeks due to high levels of circulating maternal oestrogen that makes the cartilage increasingly elastic [17].

The technique helps in bringing the alveolar segments closer thereby narrowing the cleft gap, improving the alar base symmetry, expanding the soft tissue envelope and elongating the columella $[18,19]$.

\subsubsection{Intermediate Rhinoplasty}

Intermediate rhinoplasty is reserved for procedures that are carried out prior to completion of nasal growth, in the time interval spanning between definitive lip repair and secondary rhinoplasty. The procedures are planned on the lines of conservation with the singular aim to achieve symmetry during continued nasal growth, ultimately creating a definitive platform for a more successful definitive repair.

The primary goal of surgery is to correct the abnormal position of the LLC on the cleft side so that there is no exacerbation of the deformity following nasal growth in future. It is imperative to perform a septorhinoplasty or cartilage grafting procedures in the post-adolescence age so that the nasal growth proceeds unimpeded [11].

Intermediate rhinoplasty can be carried out at two distinct time intervals [20]. One corresponds to 4-6 years of age, and this age group coincides with the timing of lip revision if required and also helps in achieving a better nasal symmetry. Also, this is the time when the peer pressure starts to mount necessitating the need for intermediate rhinoplasty in this age group. Furthermore, any lateral vestibular webbing can be dealt with preventing the obstruction of the external nasal valve.

The other instance when an intermediate rhinoplasty can be carried out is after completion of orthodontic alignment and secondary alveolar bone grafting (8-12 years). This helps in creating a solid skeletal platform to affect a longlasting correction of severe nasal deformities.

\subsubsection{Secondary or Definitive Rhinoplasty}

Secondary or definitive rhinoplasty is performed once the maxillary and nasal growth ceases, which corresponds to 14-16 years of age in females and 16-18 years of age in males [21]. The procedure has to be definitive and provides an opportunity to introduce aggressive surgical interventions like septorhinoplasty, nasal osteotomies and cartilage grafting manoeuvres without fear of jeopardising the maxillary or nasal growth.

The goals of definitive rhinoplasty are mentioned in Box 76.2 .

\section{Box 76.2: Goals of Definitive Rhinoplasty}

- Create a lasting symmetry and definition of the nasal base and tip.

- Relieve nasal obstruction.

- Manage nasal scarring and webbing.

- Correct short columellar skin if present, and augment the nasal dorsum in cases of bilateral cleft nasal deformities [1].

Most CLP patients present with maxillary hypoplasia and therefore require maxillary advancement surgery in the form of either LeFort I osteotomy, total maxillary distraction or anterior maxillary distraction. The maxillary projection can be improved with these procedures without affecting the nasal dorsum adversely [22]. These procedures also allow for forward movement of LLC and improvement of the tip projection. In scenarios such as this, definitive rhinoplasty is often carried out after addressing the skeletal discrepancies. 


\subsection{Preoperative Evaluation}

Prior to carrying out a rhinoplasty surgery, it is prudent to carry out a thorough evaluation of the nose in a meticulous manner. This when backed up with sound knowledge of nasal anatomy can bring about aesthetically pleasing results in cleft rhinoplasty.

\subsubsection{History}

It is imperative to address any patient concerns as related to symmetry of the lip and nose, nasal airway, etc. prior to carrying out a rhinoplasty surgery. Any previous nasal surgeries have to be documented accurately. The effects of such surgeries on the postoperative outcomes have to be explained to the patient beforehand.

\subsubsection{Physical Examination}

A thorough physical examination involves examining both the external appearance and the internal nasal structures.

External examination of the nose must be carried out in accordance with its position on the facial skeleton. Measurements as traced on preoperative photographs can provide a guide in the surgical planning (Fig. 76.3a-d).

Internal nasal examination proceeds in a systematic and repeatable manner and is performed using a nasal speculum to evaluate for the nasal function.

When performing the physical examination of the nose, the clinical characteristics of unilateral and bilateral cleft nasal deformities as previously described are looked up for in a systematic manner. Gunter diagrams can be a valuable aid for the purpose of preoperative planning [21].

\subsubsection{Photographic Documentation}

\subsubsection{Two-Dimensional Photographs}

Appropriate documentation of the deformity is made possible by taking preoperative photographs in all views, viz. frontal, basal, lateral and oblique views (Fig. 76.4a-f). These photographs serve diagnostic purpose as well as help in protecting the surgeon in cases of medico-legal implications. The photographs also help in explaining the goals of surgery adequately to the patient. Furthermore, the photographs can serve as a visual guide to the surgeon intraoperatively, helping in implementing the planned surgical goals precisely.

\subsubsection{Three-Dimensional Imaging}

This method requires a set of devices, viz. an optical system, digital communication network and a computer with a calculation program which helps in determining the shape of the three-dimensional object by transforming the image from analogue to digital form (Fig. 76.5a). The technique is reliable, can be safely employed in child patients due to its nonionising nature and offers both qualitative and quantitative assessments, and the digital model can be employed in the clinical setting immediately. The disadvantages include the cost, long time that is required for patient preparation and data acquisition and inability to measure bony or interactive landmarks.

\subsubsection{Radiographic Assessment}

\subsubsection{Cephalometric Analysis}

Cephalometric analysis aids in evaluating the maxillary position and its possible implications on the patient's nose [21] (Fig. 76.5b). The need for any maxillary advancement surgery and the importance of performing it before any rhinoplasty surgery should be conveyed to the patient. Cephalometric analysis also allows for evaluation of chin position [21].

\subsubsection{Computed Tomography (CT)/Cone Beam Computed Tomography (CBCT)}

CT scans of the paranasal sinuses in axial and coronal views help in defining the deformation of the septum as well as other intra-nasal structures. CBCT is an attraction alternative to $\mathrm{CT}$ with regard to decreased ionising radiation to the patient and image quality for hard tissues on par with CT. No modalities other than CT/CBCT allow for evaluation of nasal septum objectively [23] (Fig. 76.5c).

\subsubsection{Facial Casts}

Facial casts have been employed by authors to study the nasal morphology by direct anthropometry [24] (Fig. 76.5d). The technique is found to be objective and cost-effective and 


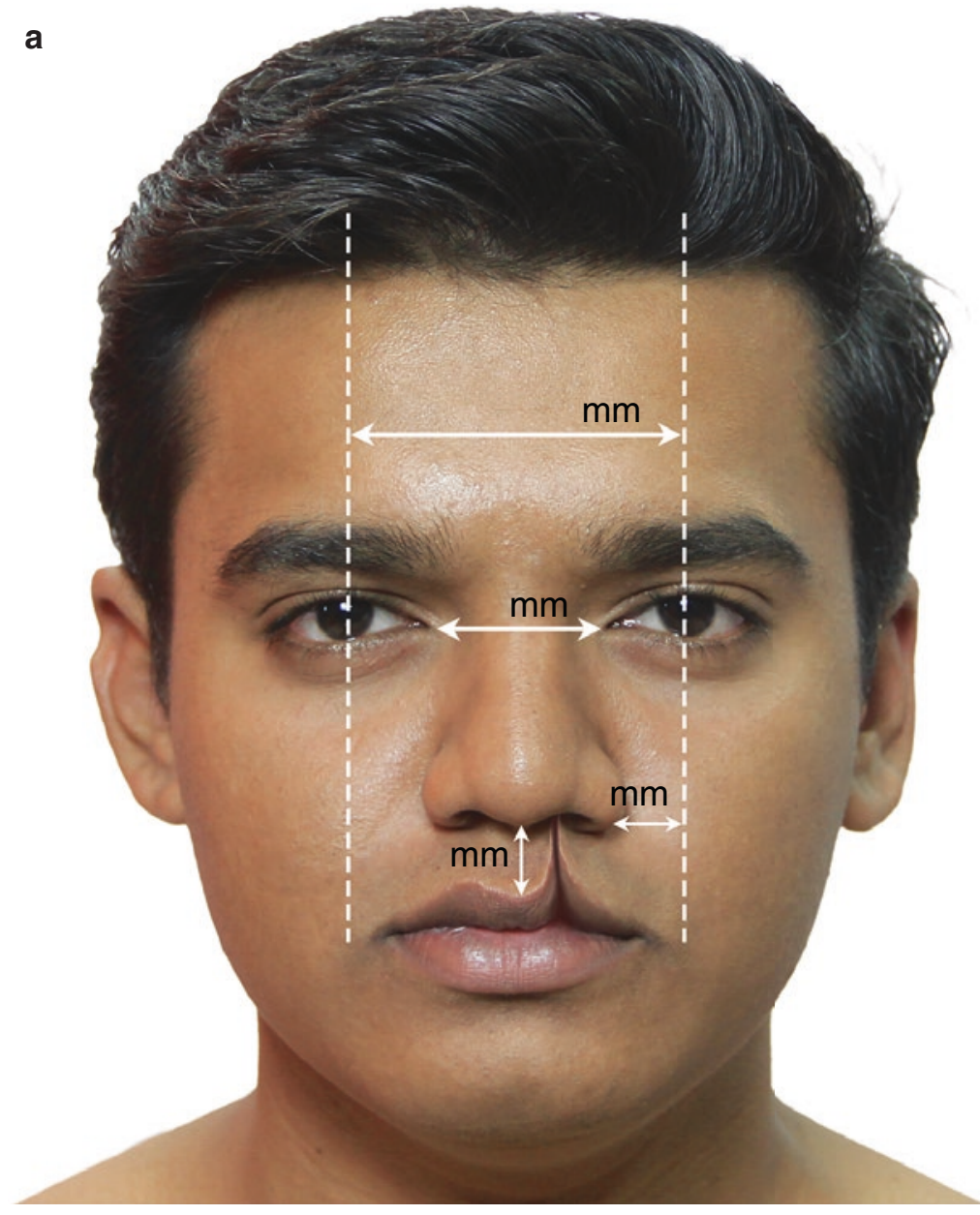

C

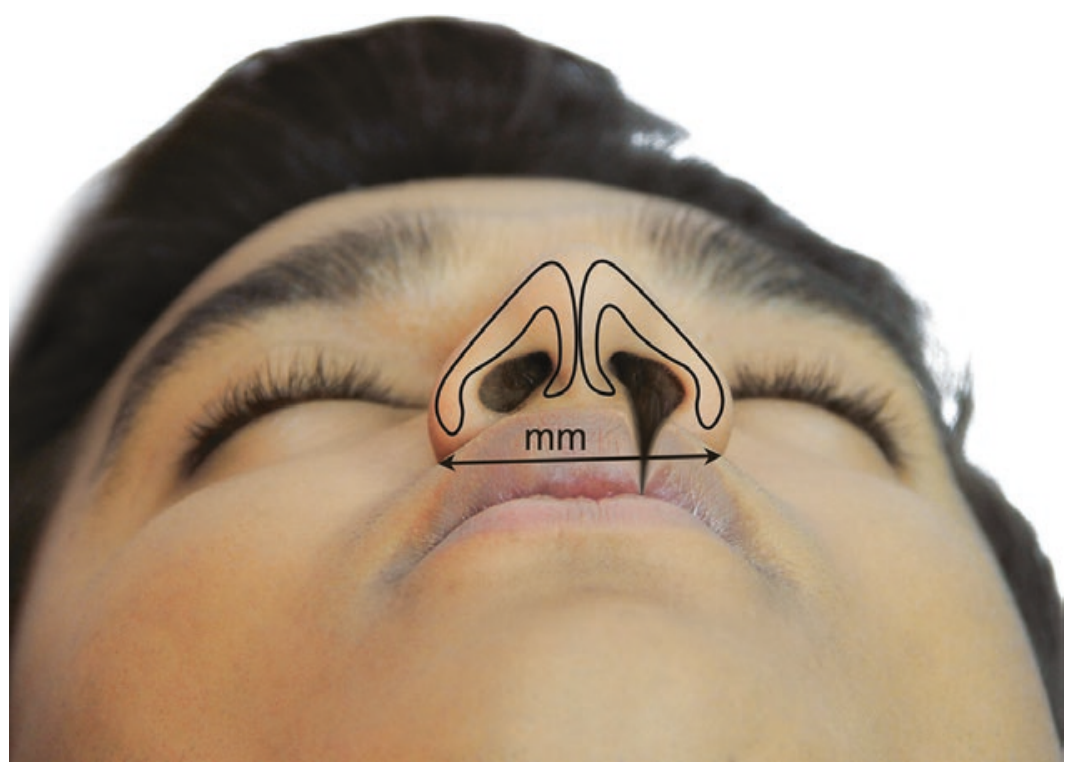

CAssociation of Oral and Maxillofacial Surgeons of India

Fig. 76.3 (a-d) Important angular and linear measurements as traced from preoperative photographs can serve as a guide for preoperative surgical planning

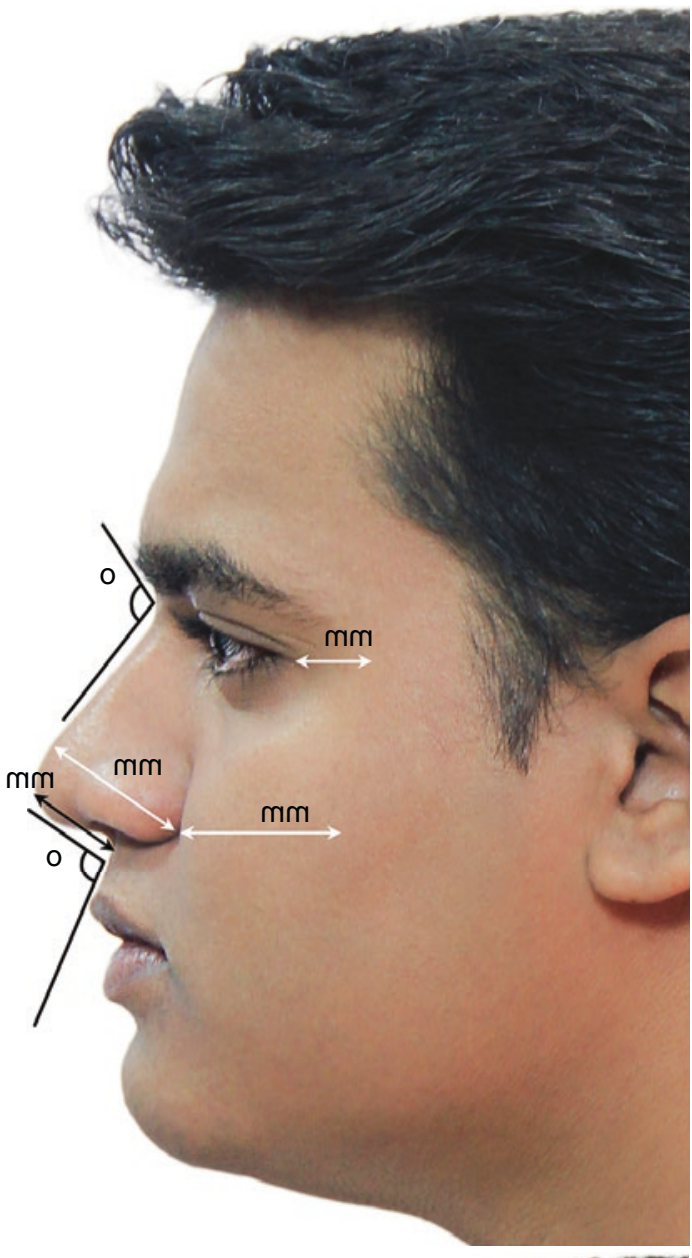

d

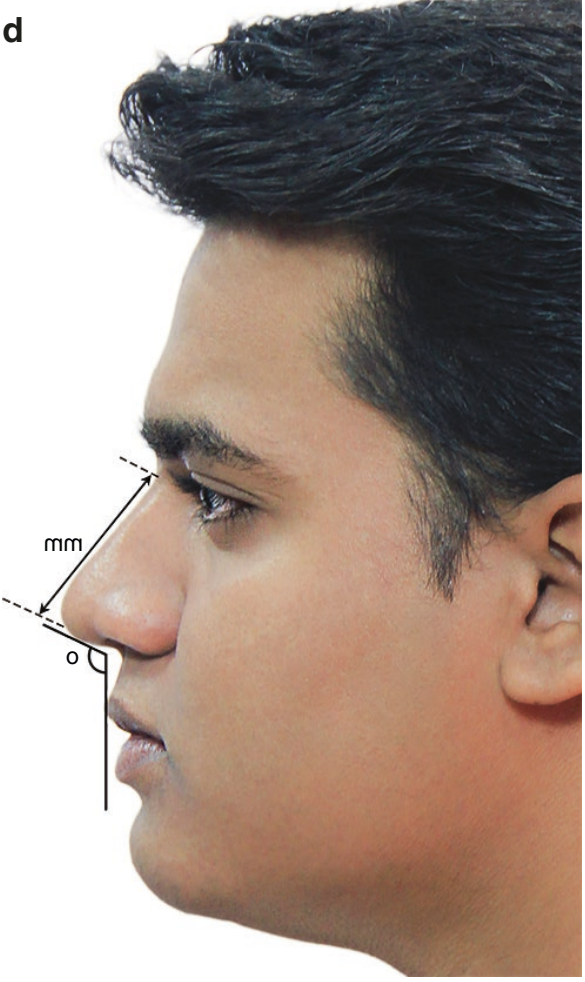



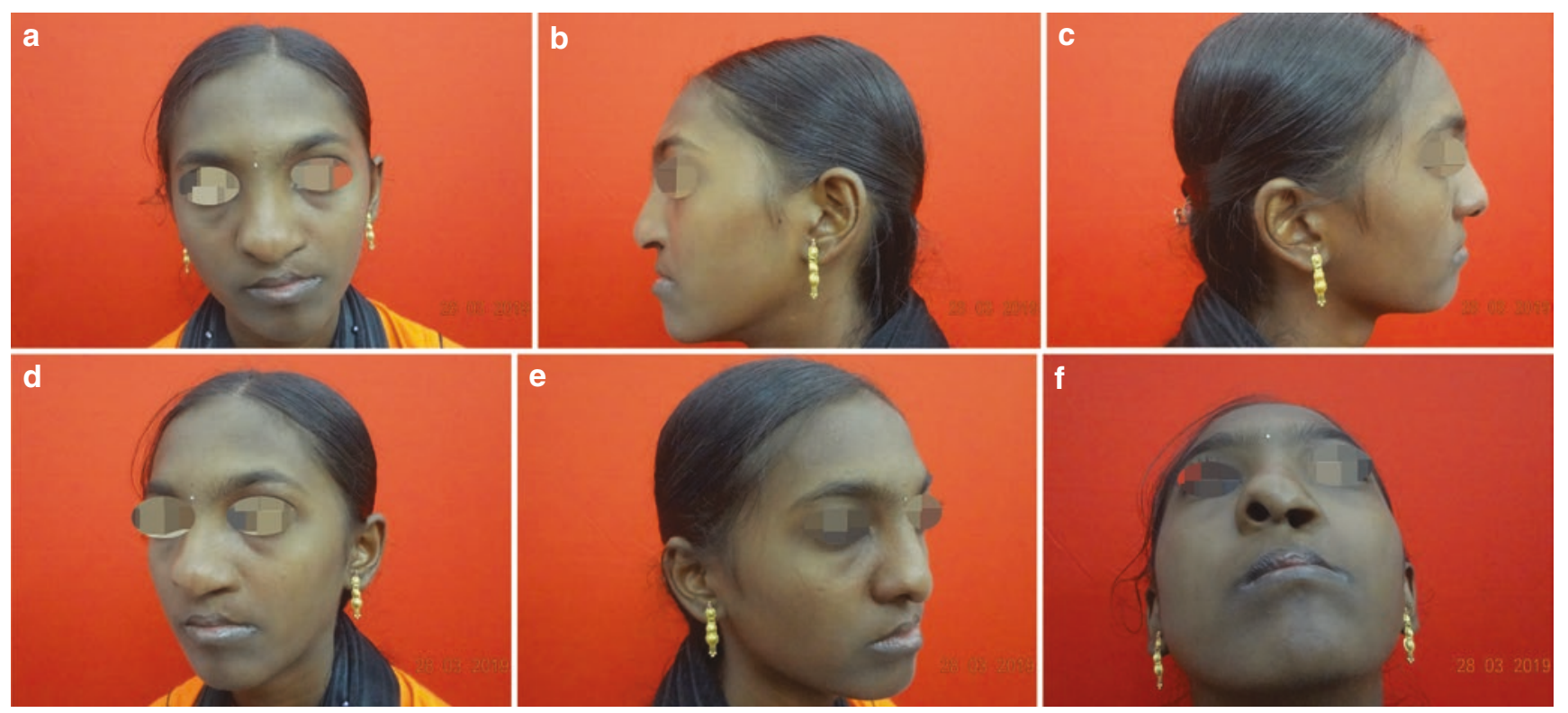

CAssociation of Oral and Maxillofacial Surgeons of India

Fig. 76.4 (a-f) Standard photographic views for cleft rhinoplasty. (a) Frontal view. (b) Left lateral view. (c) Right lateral view. (d) Left lateral oblique view. (e) Right lateral oblique view. (f) Basal view

allows precise recording of selected parameters as the soft tissues are not deformed.

\subsubsection{Video Recording}

Some authors $[25,26]$ have also resorted to video recordings that make assessment of movements possible and eliminates the need for clinical photographs as these can be generated from the video records. The disadvantages include increased time and need for trained personnel with considerable cooperation from the patients.

\subsubsection{Functional Assessment}

Function is as important as nasal aesthetics. Functional assessment can be established using rhinomanometry; however the usefulness of such an evaluation is limited.

\subsection{Surgical Correction}

\subsubsection{Surgical Approaches}

Cleft rhinoplasty can be accomplished using either an open or closed approach.
While primary rhinoplasty can be carried out using either of the two approaches, definitive rhinoplasty is almost always accomplished using an open approach.

The open approach allows for both superior visual control and enhanced surgical exposure of all the abnormal components facilitating their anatomical reconstruction under direct vision. Furthermore, the approach facilitates nasal sculpting either by suturing or by introduction and fixation of different types of grafts. The approach also helps in saving time when compared to the closed approach. When employing the open approach, a combination of bilateral marginal incisions with an inverted $\mathrm{V}$ mid-columellar incision is preferred among most surgeons [27] (Fig. 76.6a, b).

Sometimes, additional skin needs to be recruited in the columella. In such cases, the typical external columellar incision can be modified. When addressing the unilateral cleft nasal deformity, columellar lengthening can be achieved with the help of an asymmetric $\mathrm{V}$ to $\mathrm{Y}$ incision on the side of the cleft. The $\mathrm{V}$ to $\mathrm{Y}$ incision is made in the midline, recruiting the skin from the upper lip into the columella in cases of bilateral cleft nasal deformity. A viable alternative incision in cases of bilateral cleft noses is an upper lip forked flaps which achieve columellar lengthening together with narrowing of the central segment [28].

Other viable options include the use of prolabium advancement flap together with an Abbe flap, composite graft of skin and auricular cartilage and skin rim rotation flap [29]. 

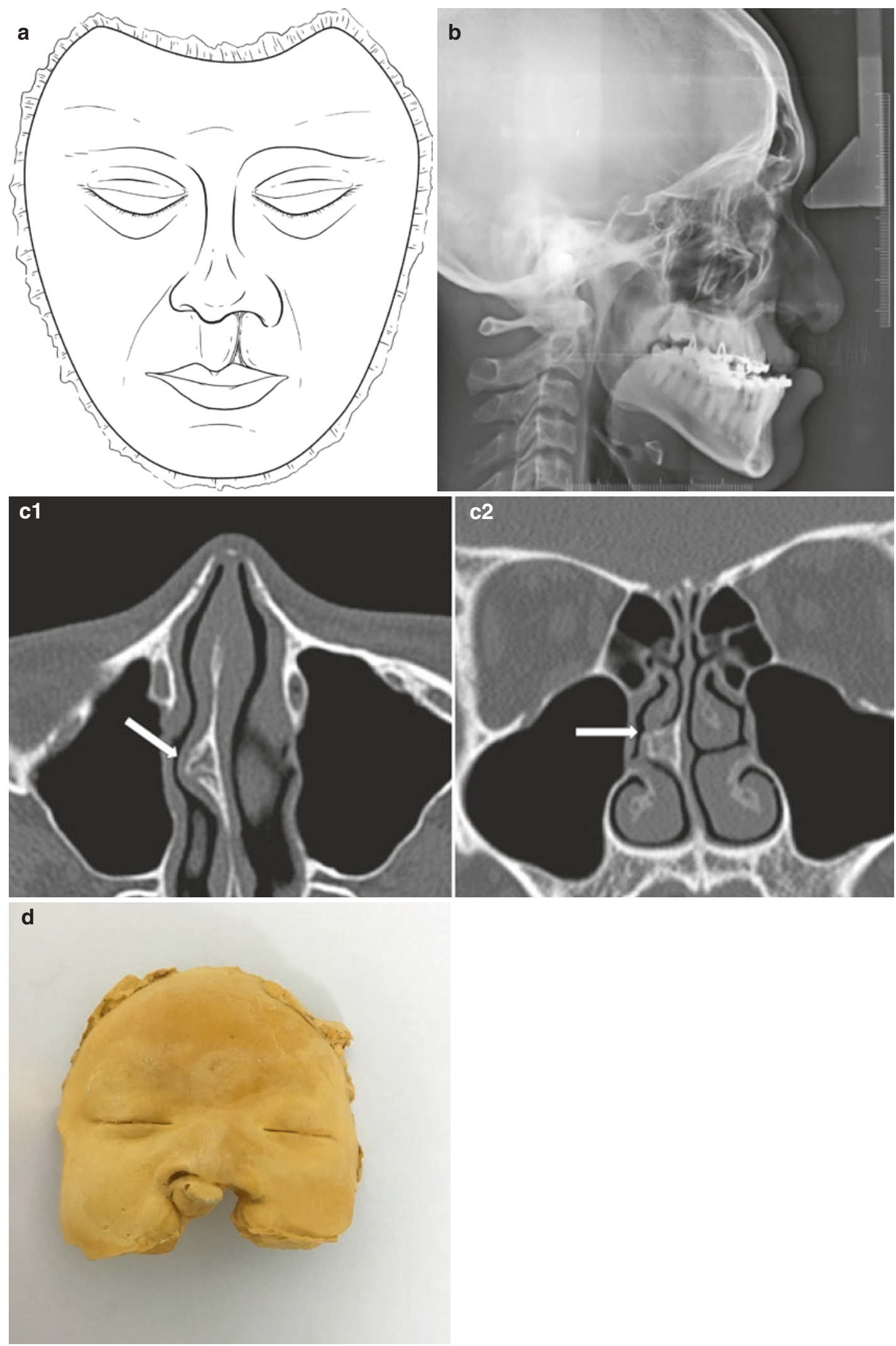

CAssociation of Oral and Maxillofacial Surgeons of India

Fig. 76.5 (a-d) Tools for preoperative patient evaluation for cleft rhinoplasty. (a) Three-dimensional model of the face. (b) Lateral cephalogram for cephalometric analysis for evaluating the maxillary and chin position prior to cleft rhinoplasty. (c) (1 and 2): Axial and coronal CT scan views allow for evaluation of the nasal septal deviation objectively (white arrows). (d) Facial cast for evaluating the nasal morphology 

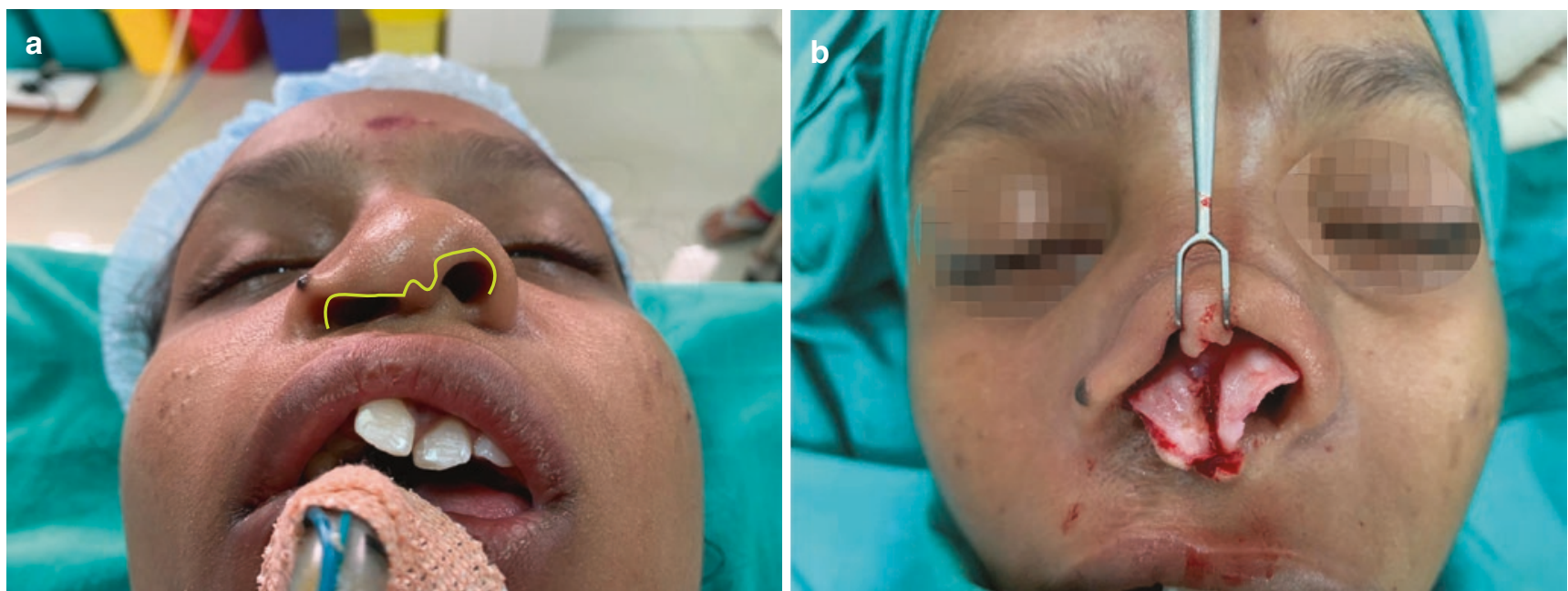

CAssociation of Oral and Maxillofacial Surgeons of India

Fig. 76.6 Open approach for cleft rhinoplasty. A combination of inverted V (a, b) transcolumellar and bilateral marginal incisions is typically employed. (a) Marking of the incision. (b) Skeletonisation of the nose using the above incision
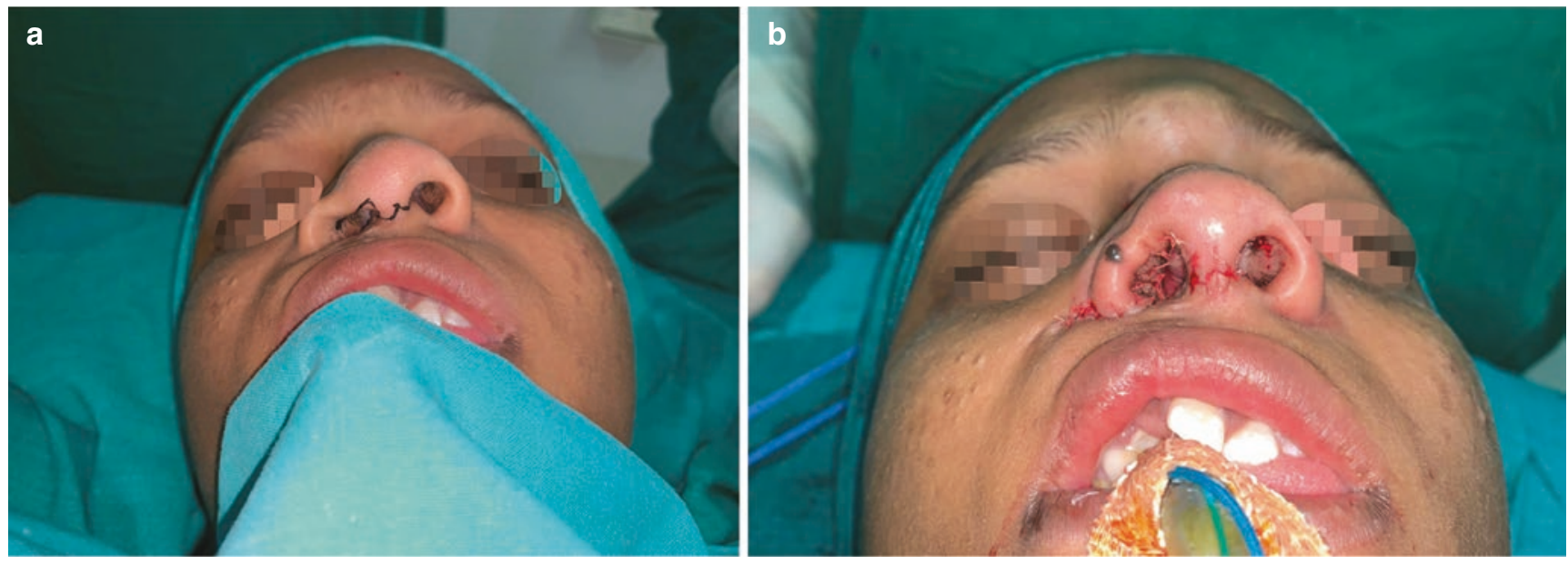

CAssociation of Oral and Maxillofacial Surgeons of India

Fig. 76.7 (a, b) Tajima and Maruyama reverse $\mathrm{U}$ incision for correction of nostril asymmetry. (a) Marking of the reverse $\mathrm{U}$ incision on to the external nasal skin on the right side of the nostril. (b) Correction of nostril asymmetry following closure (also see Fig. 76.17)

Most patients with unilateral cleft nasal deformity are often disturbed with the nostril asymmetry that accompanies such a deformity. This has been addressed using a reverse $\mathrm{U}$ incision as described by Tajima and Maruyama in 1977 [30]. The technique involves extending the marginal incision into a rim incision at the point of the alar web. The skin of the web is incorporated with the LLC flap and vestibular skin, and the flap is suspended both medially and cephalically from the LLC to the ipsilateral ULC and the septum using sutures (Fig. 76.7a, b). This helps in recruiting the external skin of the alar web to the vestibular lining which also helps in addressing the issue of deficient vestibular skin associated with unilateral cleft noses. This incision is well accepted among surgeons for correction of nostril asymmetry.

\subsection{Primary Rhinoplasty}

The aim of the surgery is to attain symmetry of the nasal tip and alar base.

\subsubsection{Unilateral Cleft Nasal Deformity}

The literature has reported a number of techniques for achieving symmetry in unilateral cleft nasal deformities primarily $[15,31]$. The salient points that are common to most of these techniques include:

- Completely freeing the soft tissue attachments of the alar base from the pyriform aperture and maxilla for symmet- 
rical repositioning of the retro-positioned alar base on the cleft side.

- Nasal tip plasty is carried out to increase the nasal tip projection. This is made possible by utilising the incisions for lip repair. Dissecting through these incisions, the skin overlying the LLC's is dissected with the help of medial and lateral tunnels, and the cutaneous attachments of the lateral crura are separated [1] (Fig. 76.8a).

- Repairing the caudal septum by attaching it to the anterior nasal spine.

- Finally, following complete closure of the lip and repositioning of the alar base, the LLC is secured in the new position using either transnasal sutures or nasal bolsters [32]. These sutures help in recreating the cleft side dome thereby increasing the nasal tip projection and improving the tip symmetry (Fig. 76.8b).

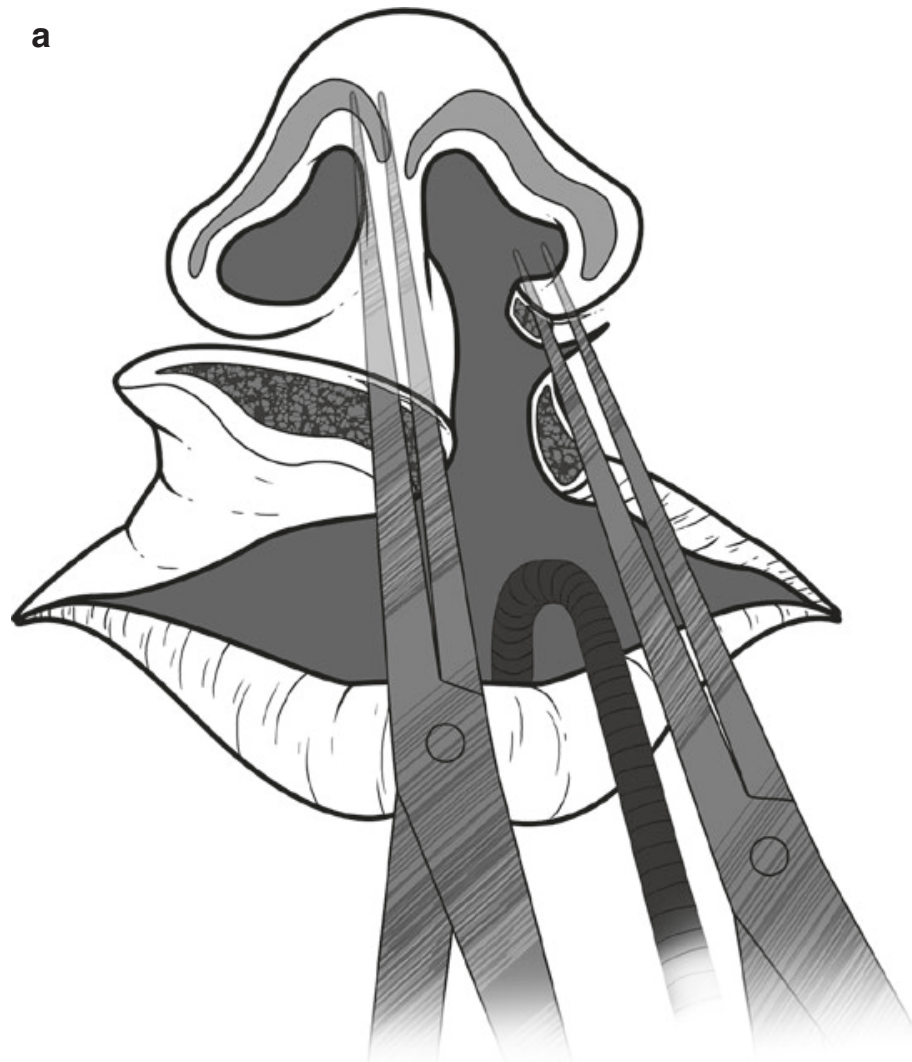

CAssociation of Oral and Maxillofacial Surgeons of India

Fig. 76.8 (a, b) Schematic representation of primary rhinoplasty in a unilateral cleft lip nasal deformity case. (a) Dissection for access to crura utilising the incisions for lip repair. (b) Recreating the cleft side nasal dome using transnasal sutures for better symmetry and projection. The sutures are made to pass through the nose, vestibular lining and

\subsubsection{Bilateral Cleft Nasal Deformity}

In bilateral cleft nasal deformities, the retro-positioned alar bases are released from the nasal lining laterally and positioned symmetrically by securing the nasalis muscle to the nasal septum on both sides. The nasal muscular ring is reconstructed as performed in the unilateral cleft noses. Nasal tip surgery is not performed at this stage but is carried out at the time of intermediate rhinoplasty [21].

\subsection{Intermediate Rhinoplasty}

\subsubsection{Unilateral Cleft Nasal Deformity}

The intermediate rhinoplasty addresses two issues in unilateral cleft nose: the asymmetric position of LLC on the side of the cleft and vestibular webbing laterally (Fig. 76.9a-d).

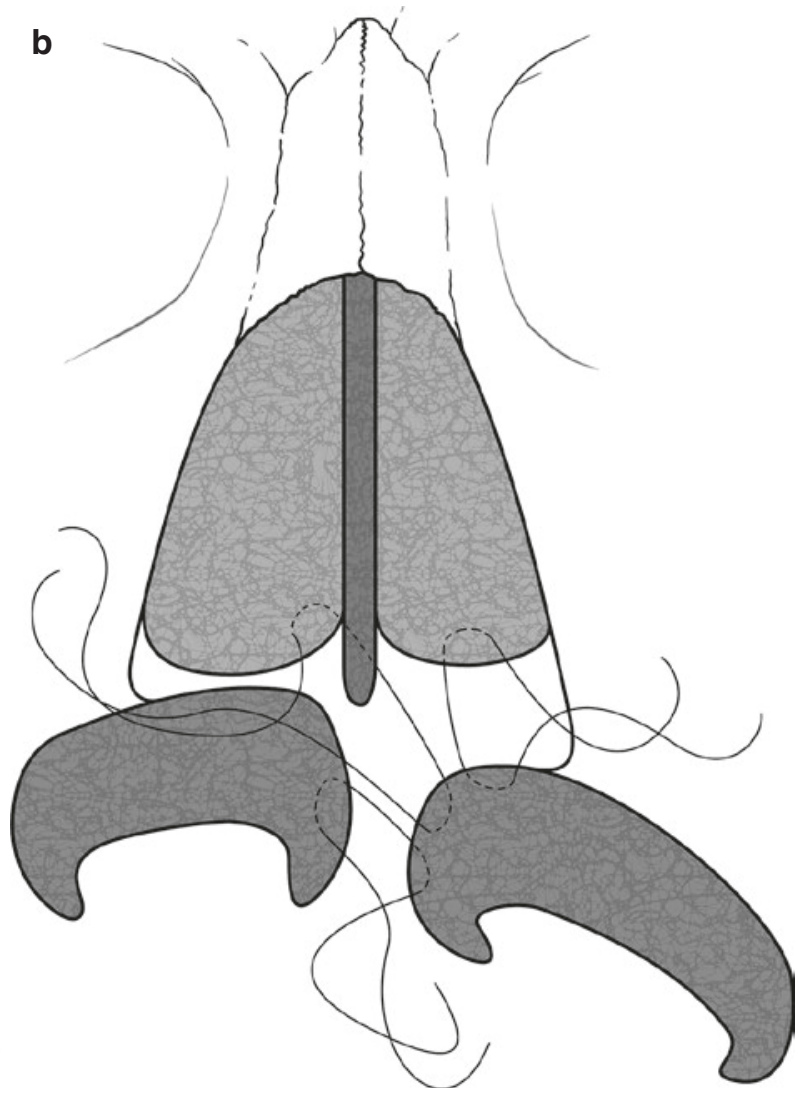

LLCs and through the nasal skin before being reintroduced through the nasal skin and ULC and sutured down within the nasal vestibule. It is important to reintroduce them through the same hole they exited to prevent necrosis of the nasal skin 

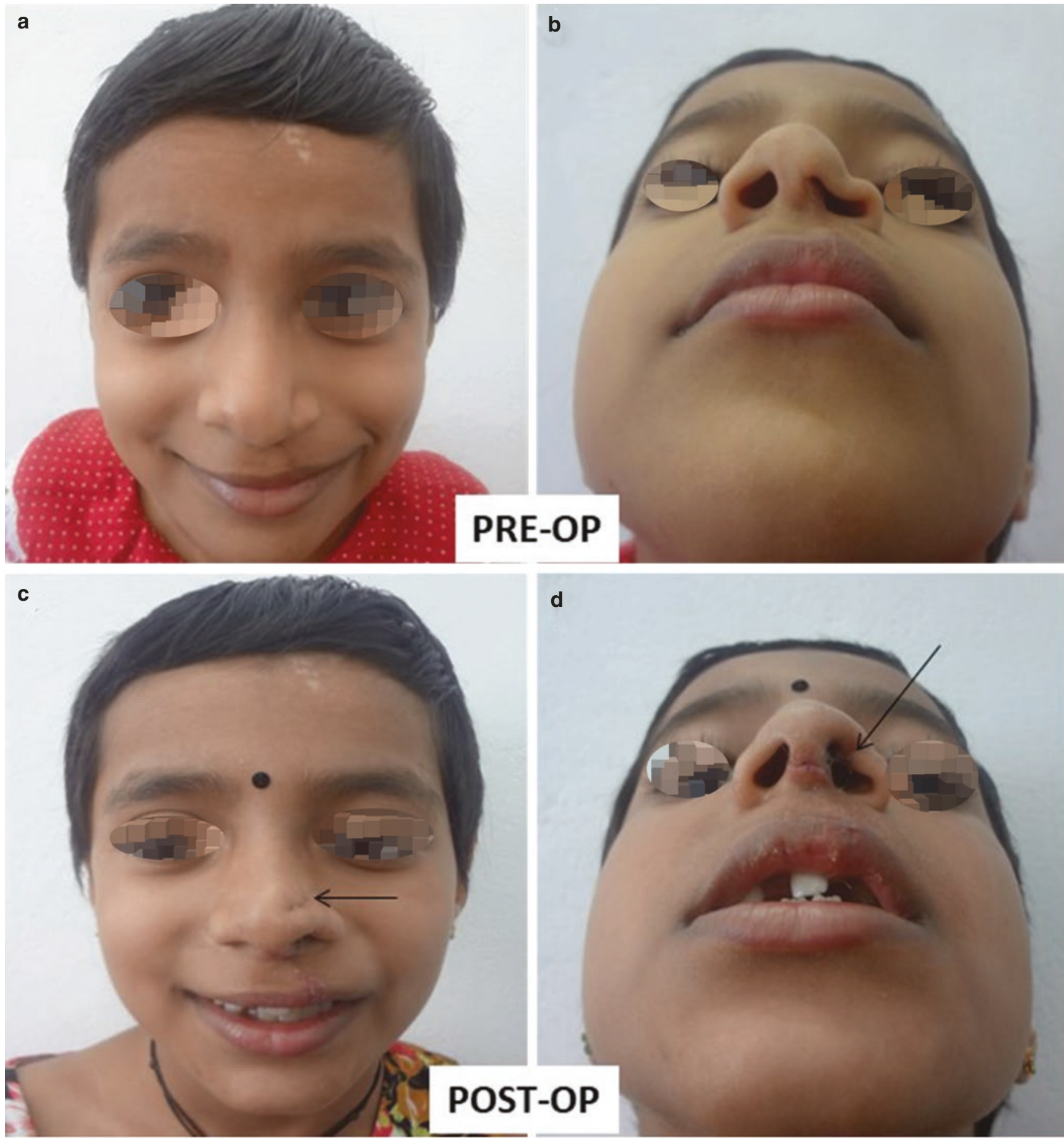

CAssociation of Oral and Maxillofacial Surgeons of India

Fig. 76.9 (a-d) A case of unilateral cleft nasal deformity in a 6-yearold child managed using intermediate rhinoplasty. (a) Preoperative frontal view. (b) Preoperative basal view showing the abnormal position of LLC on the cleft side (Left). (c) Postoperative frontal view. The

abnormal position of the LLC on the cleft side is corrected using an open approach (inverted V transcolumellar incision) and transnasal sutures (black arrow). (d) Postoperative basal view showing symmetrical positioning of the LLC on the cleft side (black arrow) 
In cases of asymmetric position of the LLC on the cleft side, an open approach is usually preferred that exposes the LLCs bilaterally so that the geometric differences between the two sides can be appreciated and subsequently corrected using suture techniques followed by closure along the columellar incision [33].

In cases of lateral vestibular webbing, a V/Y-type incision or a back cut can be carried out to affect the lateral nasal sidewall lengthening which will subsequently bring the LLC forward [1].

\subsubsection{Bilateral Cleft Nasal Deformity}

In such cases, intermediate rhinoplasty corrects the depressed LLCs as well as affects lengthening of the short columella $[1,34]$ (Fig. 76.10a, b). An open approach is employed for correction of the above-mentioned scenarios. Following exposure of the LLCs, the angle of divergence between the domes is decreased using transdomal suture, helping in increasing the projection of the nasal tip [34].

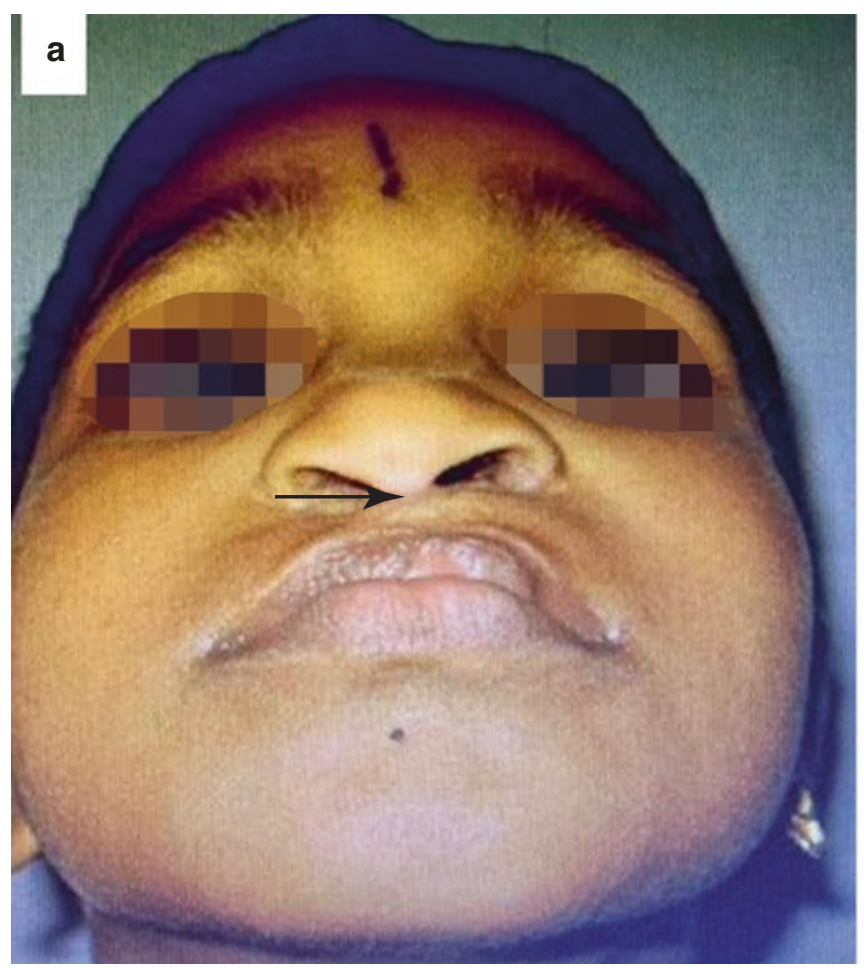

CAssociation of Oral and Maxillofacial Surgeons of India

Fig. 76.10 (a, b) A case of bilateral cleft nasal deformity in a 5-yearold managed using intermediate rhinoplasty. (a) Preoperative basal view showing the abnormal position of the LLCs as well as short columella (black arrow). (b) Postoperative basal view. One can appreciate

\subsection{Secondary or Definitive Rhinoplasty (Video 76.1)}

Despite an excellent primary rhinoplasty, secondary deformities coupled with scarring are bound to occur. These issues are tackled upon by definitive rhinoplasty. The surgeon's skill and his expertise will ultimately decide the success of primary cleft lip nose repair and the severity of secondary deformities. The success of definitive rhinoplasty depends on addressing every component of the deformity in a systematic manner beginning with the nasal base and ending with the alar base reduction.

\subsubsection{Nasal Base}

Creating a strong base for the nose represents the preliminary step in correction of either unilateral or bilateral cleft nasal deformity, the foundation for which is laid down at the time of primary cheilorhinoplasty with the approximation of the nasal floor with the lip. This is followed by addressing

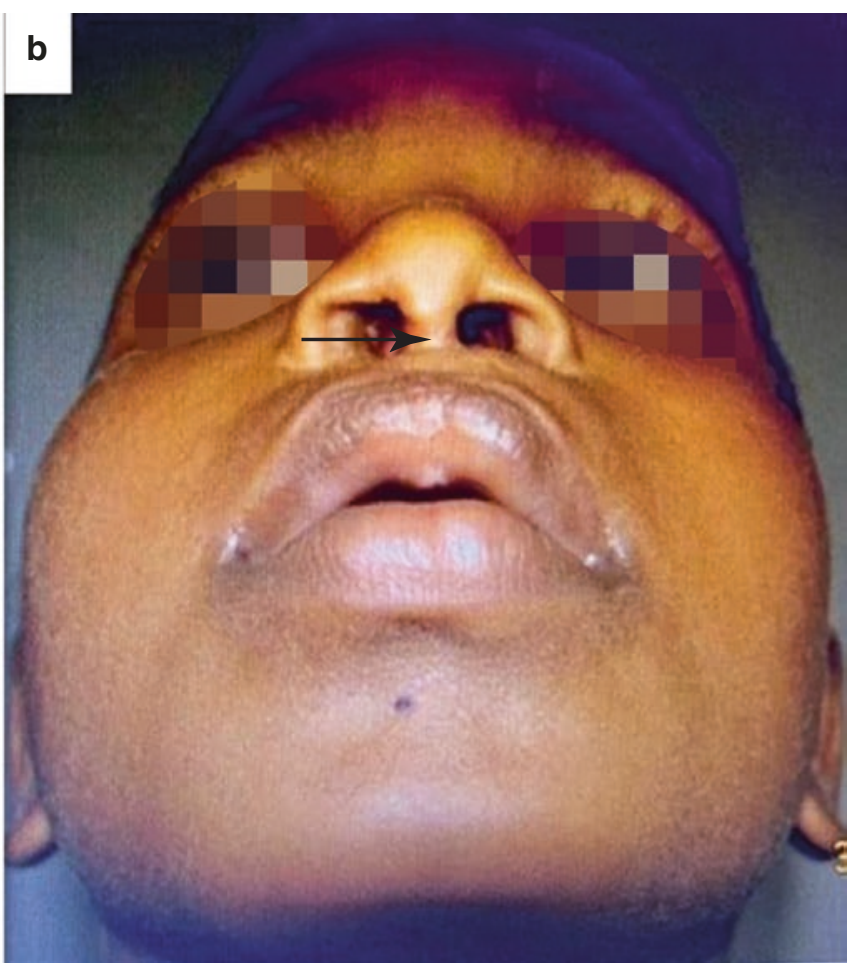

lengthening of the columella that is achieved (black arrow). The correction of LLCs is also affected bilaterally. An open approach was utilised with bilateral reverse $U$ incision to correct the horizontal orientation of the nostrils 
the skeletal deficiency in the maxilla and premaxilla and correction of the retro-positioned alar base. In some cases, the nasal sill and the nasal base might still have to be augmented at the time of secondary rhinoplasty using local tissue flaps [35].

\subsubsection{Septum}

The caudal septum is seen to deviate to the non-cleft side, bowing away from the anterior nasal spine with resultant nasal airway obstruction. This requires resection of this portion of the septum, maintaining at least $1 \mathrm{~cm}$ dorsal, and caudal septal segments in the form of a L strut to help in preserving the nasal tip and the dorsal support [21] (Fig. $76.11 \mathrm{a}-\mathrm{i})$. When doing so, more than $40 \%$ contact point must be allowed between the crest of the maxilla and $\mathrm{L}$ strut which helps by subjecting the septum to decreased load forces thereby preventing nasal deformities like saddle nose deformity or ptosis of the nasal tip from developing in the future. It is observed in most cases that despite resecting the deviated portion of the septum, the $\mathrm{L}$ strut continues to remain deviated due to residual memory that is present in the L strut. In such cases, sutures can be placed through the ULC and the septum applying force in the direction opposite of the deviation to aid in correcting the asymmetry [36]. In cases of severe septal deviation, one needs to resort to using caudal septal extension graft as struts along the dorsal margins followed by surgical repositioning of the caudal septum [37, 38] (Fig. 76.11). The resected portion of the septal cartilage can itself be used as a spreader graft. In cases where the resected septal cartilage is inadequate, one can use rib cartilage as a spreader graft. The caudal portion of the $\mathrm{L}$ strut is secured to the anterior nasal spine with the help of sutures. Some surgeons also prefer to make a notch in the anterior nasal spine to which the L strut can be secured. If there exists any residual memory in the septal cartilage after securing it to the nasal spine, it can be relieved by cartilage scoring with the help of a no. 15 blade.

Access to the caudal nasal septum is achieved using an open approach and by dissecting between the medial crura of the LLCs [21]. From this point onwards, a sub-perichondrial flap can be developed. Make sure that the dissection is in the proper plane. The blue appearance of the septal cartilage serves as a guide to correct plane of dissection. The mucoperichondrial flap should be cautiously raised without perforating the surrounding mucosa to provide superior coverage for a large septal extension graft especially from the rib.

\subsubsection{Middle Third of the Nose}

The middle third of the nose has poor support on the side of the cleft and therefore the ULCs tend to collapse resulting in internal valve dysfunction which affects the patient's ability to breathe normally. In such instances, spreader grafts placed between the septum and ULCs on either side and stabilised using sutures can help open the internal nasal valve and improve breathing [39, 40] (Fig. 76.11i).

\subsubsection{Nasal Tip or LLCs}

Once the caudal septum is stabilised, attention is shifted to the correction of asymmetric LLC and the nasal tip complex. Various techniques are advocated for the same.

- Cephalic trimming: Wide LLCs can make the nose appear asymmetric. In such cases, following surgical exposure of the LLCs via an open approach, small cephalic strips of LLCs can be excised advocating more excision on the larger side and leaving at least $5 \mathrm{~mm}$ for support. This manoeuvre narrows a bulbous nasal tip and improves symmetry. Cephalic trimming is followed by correction of the septal deviation by resection and replacement (Fig. 76.12a).

- Septal extension graft: A strong septal extension graft helps in providing support to the nasal tip and improves the tip projection by rotating an acute nasolabial angle which is the consequence of tip ptosis back to normal $[22,41]$. The graft is ideally sutured in between the medial crura of LLCs and the caudal septum (Fig. 76.12b). Prior to suture stabilisation of the septal extension graft, the medial crus of LLC on the cleft side is advanced superiorly to match the vestibular dome height of the non-cleft side. This is then secured to the extension graft using mattress sutures (Fig. 76.12c). In cases where spreader grafts are used to relieve the internal nasal valve collapse, the extension graft can be secured to the spreader grafts. In such cases, the base of the nose is fortified with bolster sutures from medial crus to the septal extension graft. The strut (extension graft) is ideally placed slightly behind the medial crura to prevent the columella from either looking too wide or feeling too firm for the patient [39]. A good tip support entails extension of the septal extension graft for at least $4-5 \mathrm{~mm}$ beyond the septum maintaining a thickness of at least $1 \mathrm{~mm}$. This also helps to resist deprojection from the resulting scar tissue that will form in this region. 

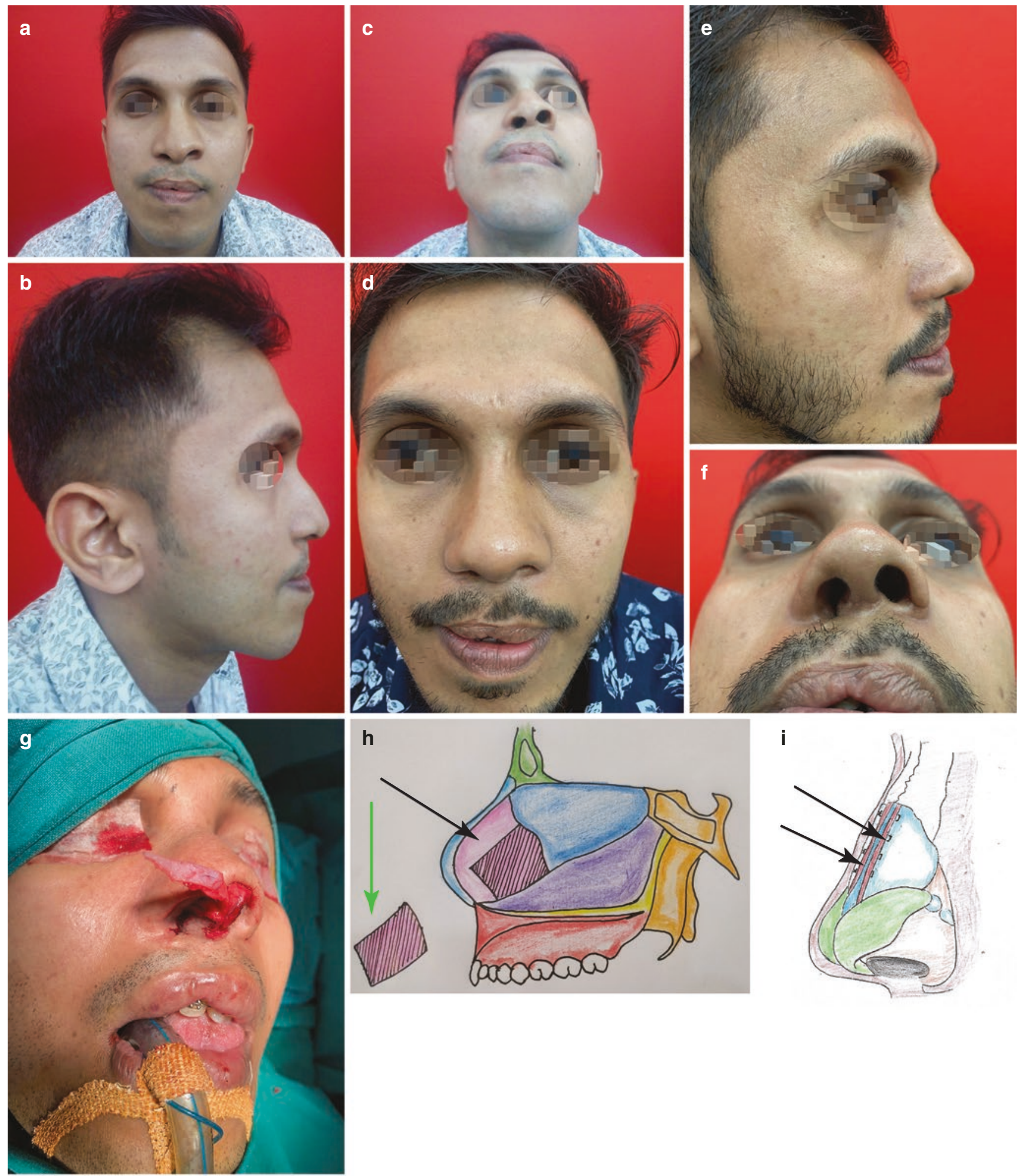

CAssociation of Oral and Maxillofacial Surgeons of India

Fig. 76.11 (a-i) 22-year-old patient with unilateral cleft lip and palate before $(\mathbf{a}-\mathbf{c})$ and 2 months after $(\mathbf{d}-\mathbf{f})$ open rhinoplasty performed to correct the severely deviated caudal septum. (g) Intraop picture showing batten grafting. (h) Resection of septal cartilage in cases of severely deviated nasal septum, maintaining an L shaped contact (black arrow) for preserving tip and dorsal support. The resected portion can be utilised as a septal extension graft (green arrow). (i) Spreader grafts placed between ULCs and nasal septum (black arrows) 
a1 Before

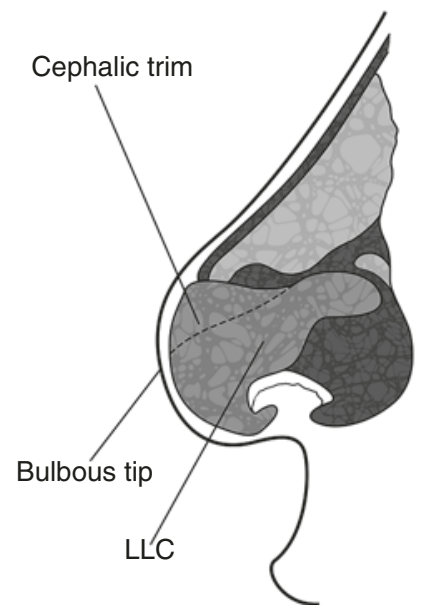

a2

After

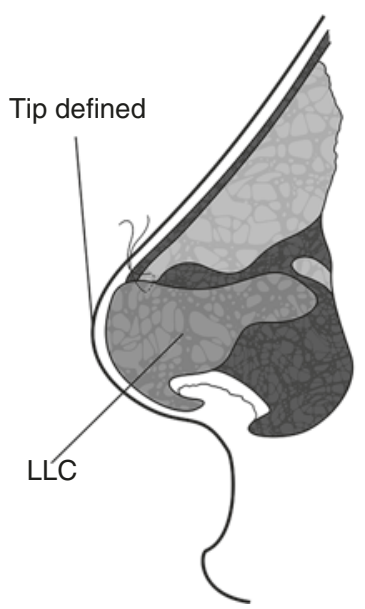

b

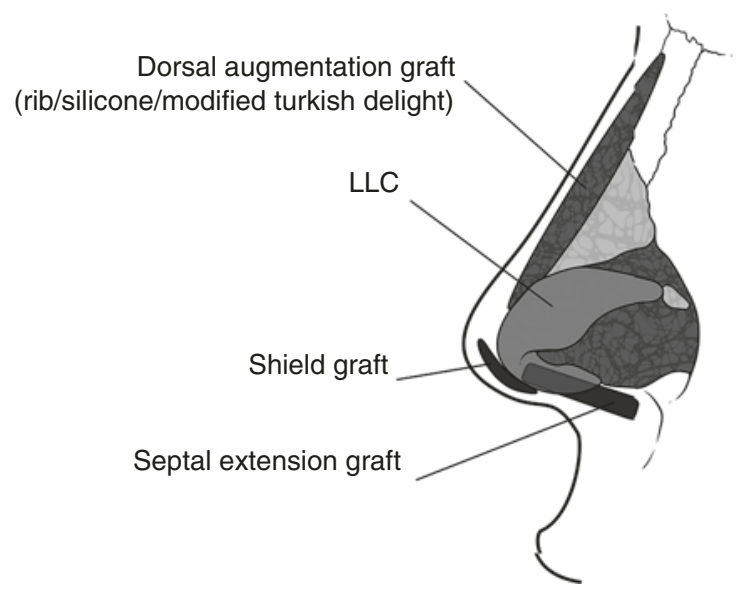

c2 c1

Major projection increase using lateral crural steal technique with columellar strut from rib cartilage/septal cartilage

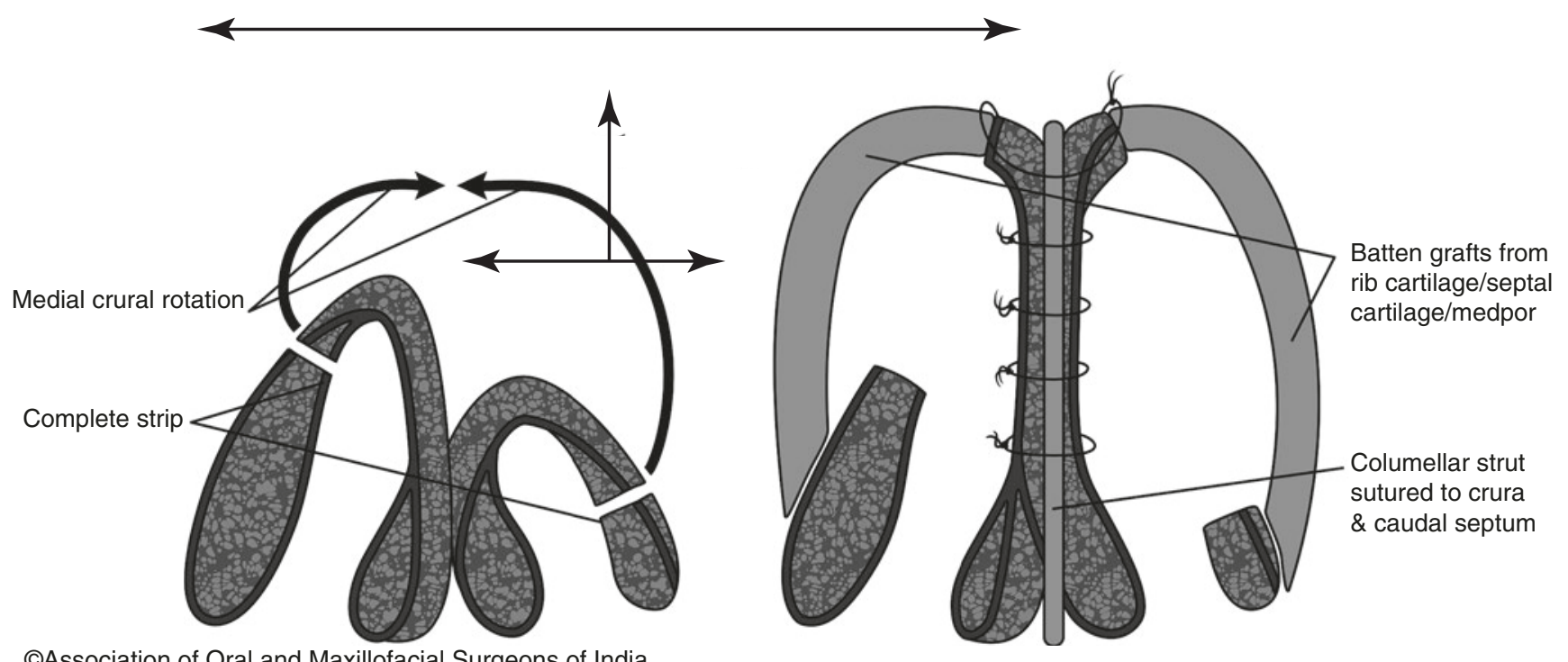

(C)Association of Oral and Maxillofacial Surgeons of India

Fig. 76.12 (a-c) Schematic representation of techniques for correction of asymmetric LLCs and nasal tip complex. (a1, a2) Cephalic trimming (before and after). (b) Shield grafts, caudal septal extension grafts

for improving the symmetry and projection of the nasal tip. Dorsal nasal augmentation is also been shown. (c1, c2) Lateral crural steal technique 
- Lateral crural steal or advancement flaps: The medial crus of the LLC on the cleft side is shorter in vertical length, whereas the lateral crus is longer with a horizontal orientation as compared to the non-cleft side. In such cases, lengthening of LLC on the cleft side is achieved using the lateral crural steal technique which requires cutting of the longer part of the lateral crus of the LLC on the cleft side and shorter part of the lateral crus of LLC on the non-cleft side [39] (Fig. 76.12b). This facilitates utilisation of the longer crural flap on the side of the cleft for increasing the nasal tip projection on the cleft side thereby contributing to improved nasal tip symmetry. The lateral crura are then reconstructed using either robust cartilage struts or batten grafts in onlay or inlay fashion.

- Shield graft: These grafts are utilised to accentuate the tip projection further as well as improve the symmetry and tip shape (Fig. 76.12b).

In bilateral cleft nasal deformities, LLCs of either side need repositioning with tip suture techniques. In cases of weak cartilages, septal extension grafts as columellar struts as well as in onlay position need be used for ideal projection [42]. Large nasal tip can benefit from cephalic trimming of both LLCs. The goal is to decrease the angle of divergence between the domal points of the lower lateral cartilages, cre-

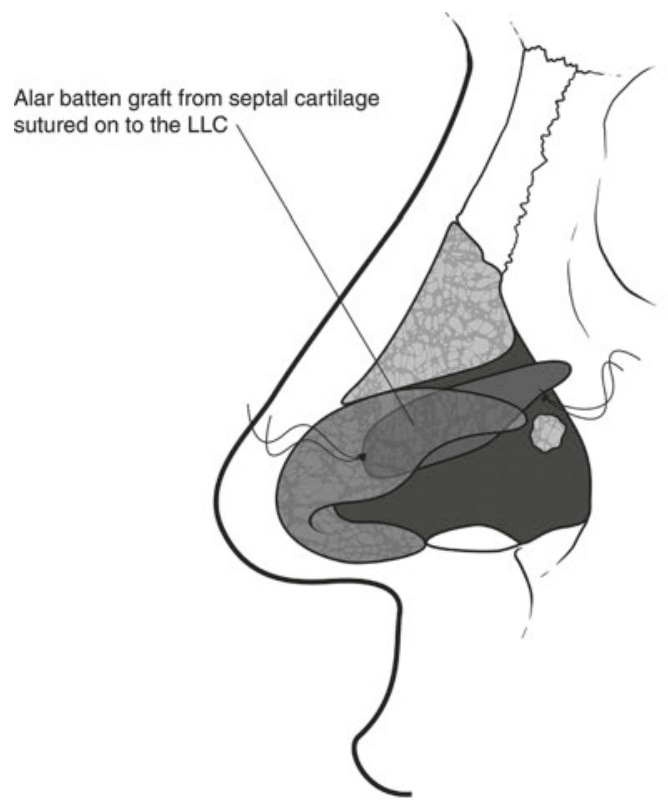

CAssociation of Oral and Maxillofacial Surgeons of India

Fig. 76.13 Alar batten grafting demonstrated in a case of unilateral cleft nasal deformity. The graft fortifies the LLC and removes the concavity of the same (Refer Fig. 76.17i) ate a more defined nasal tip and provide a strong nasal framework for better tip projection.

\subsubsection{Alar Rim (Lateral Crus of LLC)}

The LLC on the cleft side has poor skeletal support on the medial and lateral sides which makes the LLC concave with an introverted contour to the ala [43]. This concavity can be managed with different techniques, viz. suture techniques using horizontal mattress sutures, underlay alar batten grafts, onlay grafts and autocartilage flaps [44]. The lateral crus of LLC can also be dissected from the underlying vestibular skin, removed, flipped and resutured in a convex fashion.

Alar batten grafts either are placed below the residual lateral crus as underlay graft or can be placed above it as an onlay graft. This graft strengthens the lateral crus of the LLC and removes the concavity of LLC [39] (Fig. 76.13). Suture techniques such as horizontal mattress sutures also strengthen and flatten the lateral crus of the LLC. Lastly, the cephalic margin of the LLC can be made into an advancement flap which can be advanced to provide support to the remaining LLC. Each of these techniques provides support to the lateral crus of the LLC and fortifies the external nasal valve.

\subsubsection{Nasal Dorsum and Nasal Osteotomies}

The following issues are observed when addressing this area in definitive rhinoplasty.

- Flat and under-projected dorsum deviating away from the cleft: The authors' preferred technique for addressing this issue is by using a dorsal onlay graft from rib or modified Turkish delight. In modified Turkish delight technique, the authors use morselised Medpor mixed with autogenous blood and wrapped in Surgicel to affect dorsal nasal augmentation [45] (Figs. 76.12b and $76.14 \mathrm{a}-\mathrm{d})$. This cancels out the need to carry out harvesting of the rib cartilage and there eliminates the donor site complications associated with the same. Although silicone implant can also be used for this purpose, there is increased possibility of infection, graft migration or displacement or possible extrusion. It should be noted that the dorsal nasal pocket dissected should just accommodate the implant so that the implant fits snugly without much displacement or migration.

- Dorsal humps: The dorsal hump usually peaks at the region of the rhinion where the nasal bones and ULC join. 

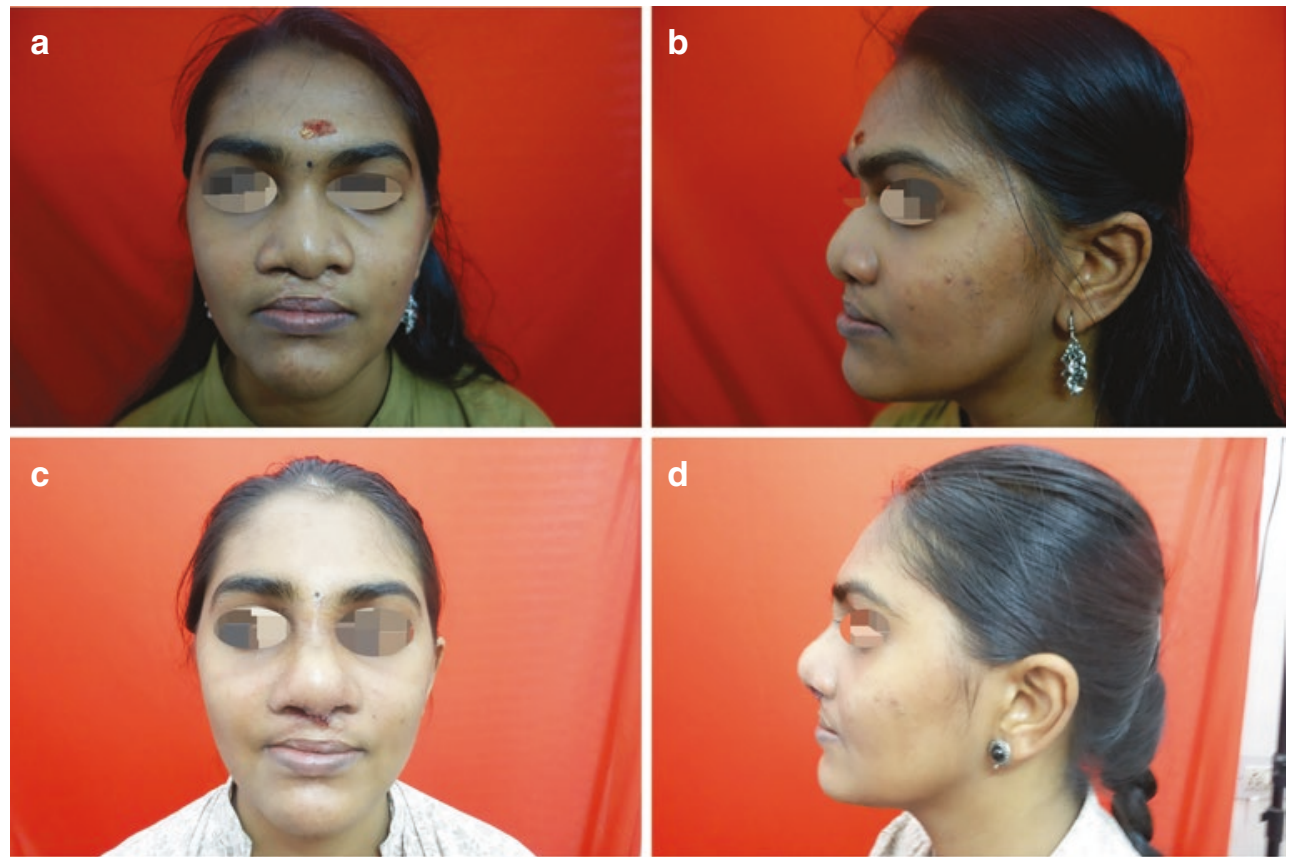

e1

e2

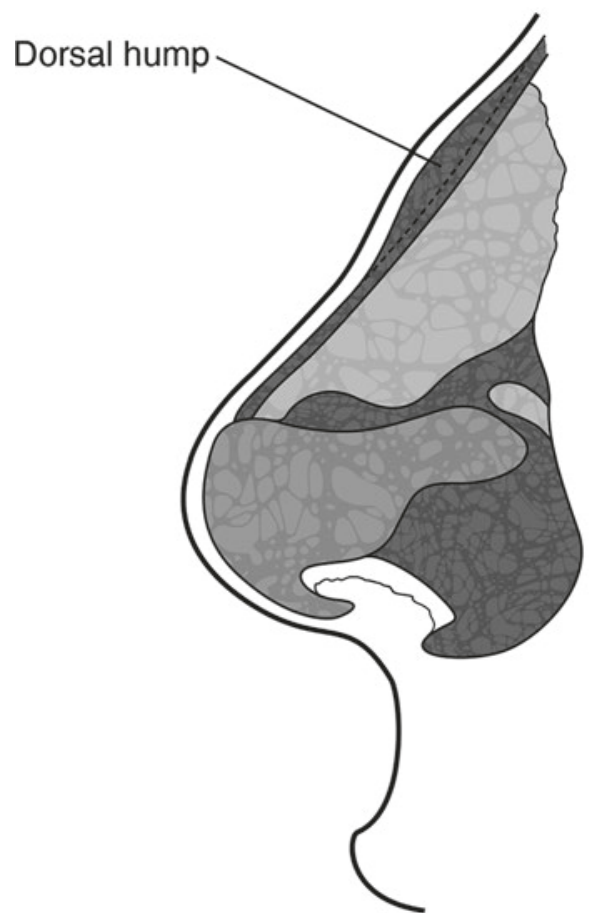

Fig. 76.14 Addressing the nasal dorsum and nasal osteotomies. A case of flat and under-projected dorsum managed using modified Turkish delight technique. (a, b) Pre op frontal and lateral. (c, d) Post op frontal

and lateral. (e1, e2) Schematic representation of dorsal hump reduction. (f, g) Schematic and clinical lateral nasal osteotomies 


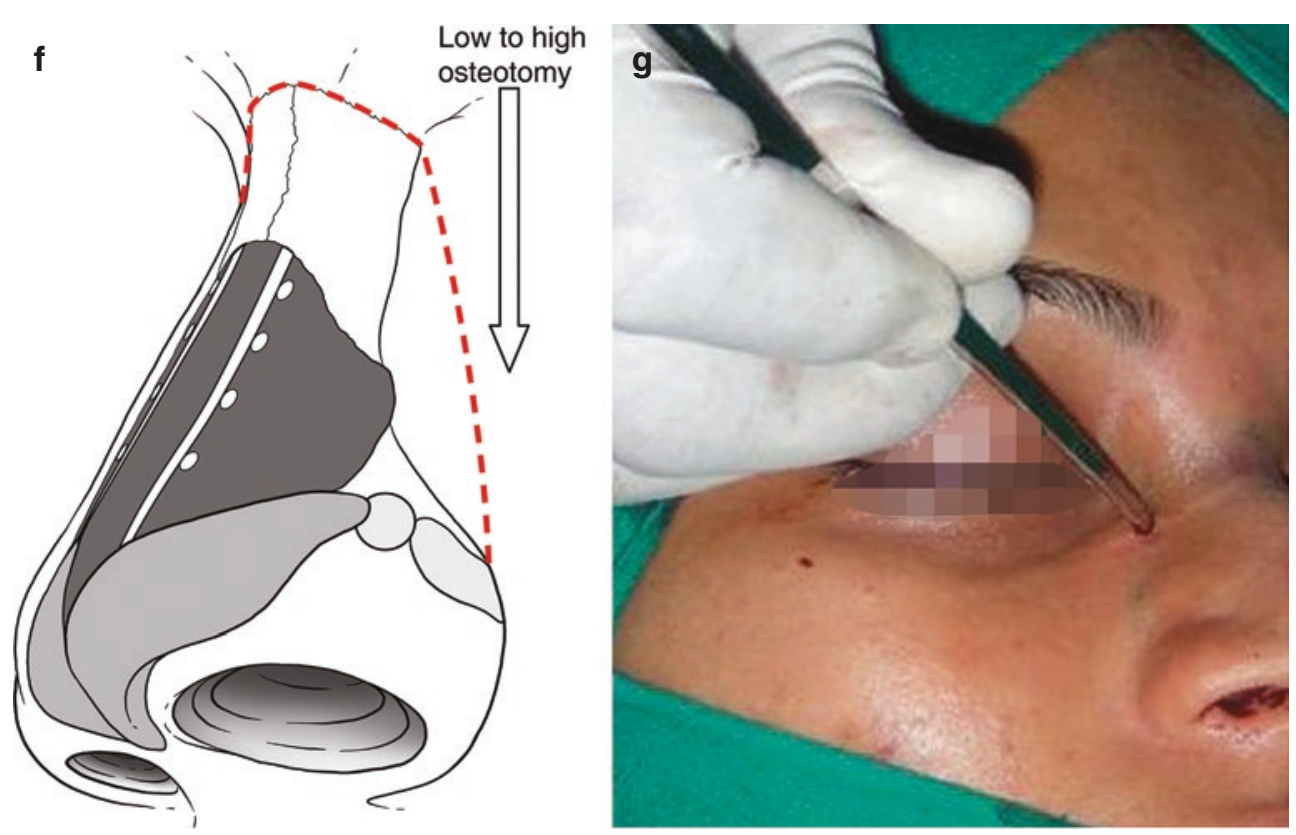

(C)Association of Oral and Maxillofacial Surgeons of India

Fig. 76.14 (continued)

Dorsal hump should be addressed in conjunction with other aspects of the nose, or else an open roof deformity will be the consequence. The correction is carried out by reduction of the bone by rasping and the ULC using either scissors or number 15 blades (Fig. 76.14e).

- Thick and wide nasal bones with deviation towards the non-cleft side with wide dorsum: Such cases require either lateral or paramedian osteotomies to narrow the dorsal width and bring about symmetry. The authors' preferred technique for lateral osteotomies is by introducing a $2-3 \mathrm{~mm}$ osteotome transcutaneously to create micro punctures along the planned osteotomy going from low to high [42] (Fig. 76.14f, g). The same can also be carried out by introducing the osteotome transnasally. If this does not affect narrowing of the dorsum adequately, then the authors resort to paramedian osteotomies to create an open roof deformity followed by in-fracturing the nasal bones. This manoeuvre almost always requires placement of spreader grafts to prevent collapse of the internal nasal valve.

\subsubsection{Piriform Rim and Pre-maxilla Augmentation}

Cleft noses whether unilateral or bilateral present with skeletal deficiency in the region of the premaxilla and piriform rim which brings about posteroinferior displacement of the nose. If this area is left unattended, the final result is bound to be asymmetric despite addressing all the other aspects of rhinoplasty well [39]. This area can be augmented using a portion of the rib graft and securing it with a screw (Fig. 76.15). This allows for improving the anterior projection. Other options include the use of silicone implant, cortical one or fat grafting [21].

\subsubsection{Nasal Alae}

The nasal alae in cleft noses as discussed previously are usually displaced in a lateral and inferior direction. Correcting the abnormal orientation of the nasal alae represents the concluding steps in definitive rhinoplasty. This is usually achieved using two techniques, viz. $\mathrm{V}$ to $\mathrm{Y}$ advancement and Weir procedure (alar resection) along the alar facial groove [46-48]. These two procedures need to be supplemented with augmentation of the piriform rim as well as vertical enlargement of the nostril on the cleft side in order to achieve true symmetry. Vertical enlargement of the nostril can be achieved using skin grafts or composite grafts just inside the ala. Superior results are possible despite not addressing the nostril except from the basal view which will make the vertical height discrepancy of the nostril evident. Weir procedure is used in cases of excess skin laterally and allows for symmetrical correction of the alar base on the cleft side nostril which is usually longer and elongated (Fig. 76.15a-g). It also provides access for carrying out augmentation of the piriform rim using grafts. Nostril retainers are often sutured in place for the purpose of helping in moulding and maintaining the nasal sill. 

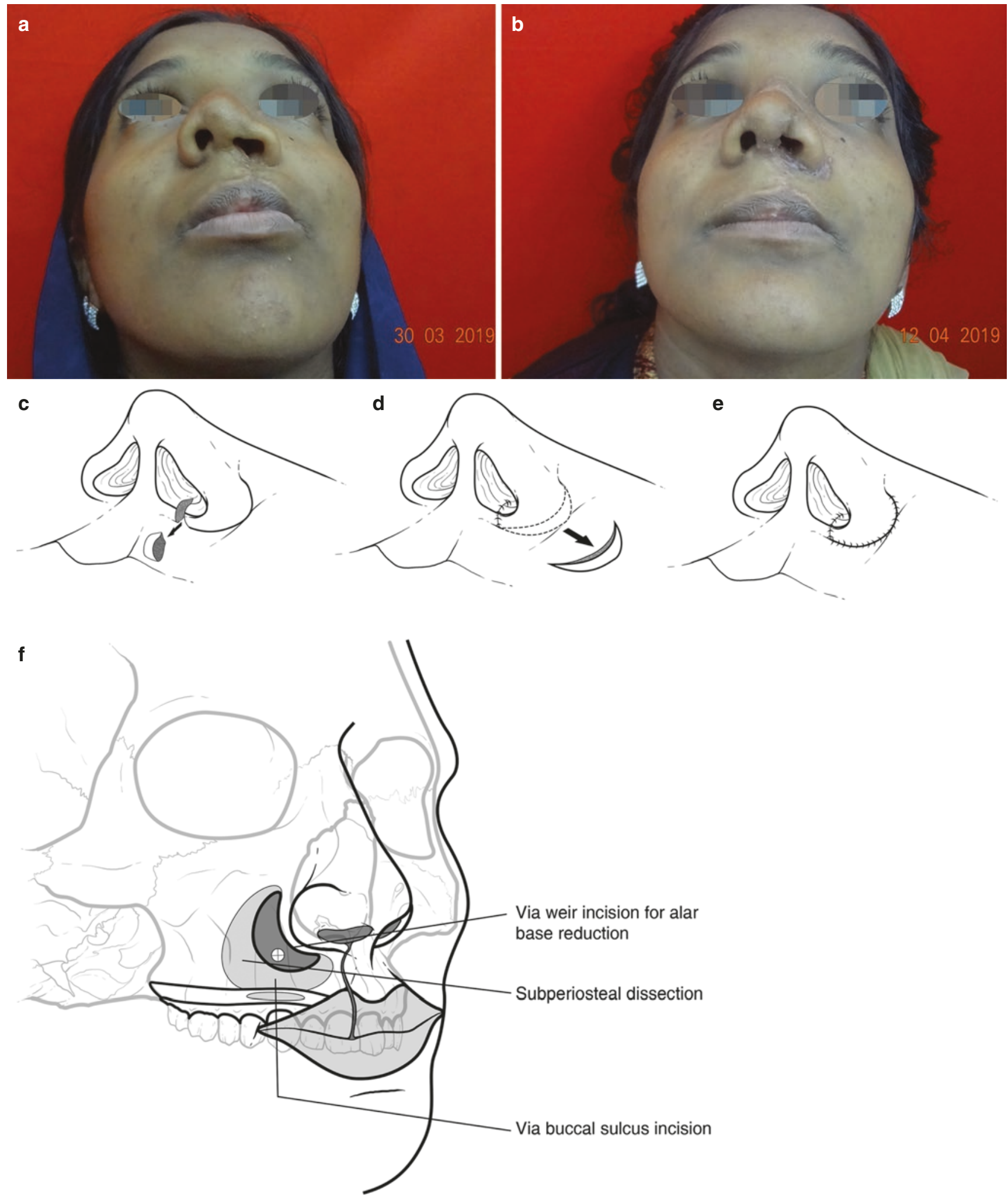

CAssociation of Oral and Maxillofacial Surgeons of India

Fig. 76.15 (a-f) Piriform rim augmentation and alar base reduction using Weir procedure. (a, b) Pre op and post op basal views. (c) Alar base resection. (d) Peri alar resection. (e) Closure. (f) Piriform rim augmentation 


\subsection{Use of Grafts in Definitive Rhinoplasty}

Grafts are pivotal to the long-standing success of definitive rhinoplasty in terms of nasal aesthetics and function. Autologous tissue is the norm and always preferred over synthetic substitutes like Medpor and silicone which presents with higher incidences of infection, displacement as well as possible extrusion. Among the autologous options available, cartilage (harvested from septum, auricle or rib) and bone (harvested from cranium, rib or iliac crest) are widely used.

Cartilage grafts harvested from the septum have the advantage of being located in the same surgical field, requiring no additional incisions and therefore preventing any additional donor site morbidity. Furthermore, simultaneous correction of septal deviations is possible with the use of this graft. The disadvantages include minimal amounts of cartilage available for grafting and presence of residual memory subjecting it to deformation. When the amount of available septal cartilage is inadequate, auricular cartilage can be the source of grafting. It may offer a large area for graft harvesting, and usually does not induce local sequelae. When larger amount of cartilage is needed especially for the purpose of dorsal augmentation, rib cartilage is an excellent source especially from the right seventh, eighth or ninth rib. This cartilage is present in abundance, is quite sturdy and robust, resists deformation by scar contracture, is easy to shape and also provides superior support for optimising the nasal projection [39]. The disadvantages include graft warpage, increased operating time, visible external scar, post-operative pain and risk of pneumothorax. Another disadvantage is ossification of cartilage in older patients [39].

Cartilage grafts are classically divided into contouring grafts and structural grafts.

\subsubsection{Contouring Grafts}

These grafts are added to the native osteocartilaginous nose in the coronal plane to improve upon the existing nasal aesthetics. Two most common sites for placement of these grafts are the dorsum and the infratip regions of the nose which help in optimising the tip projection. These grafts are stabilised using either resorbable or non-resorbable sutures or glue. Examples of contouring cartilage graft include dorsal onlay graft or shield-type tip graft.

- Dorsal onlay graft: It is used for dorsal nasal augmentation. The rib cartilage is the obvious choice. We have also utilised the modified Turkish delight (diced Medpor mixed with autologous blood and wrapped in Surgicel) for the same purpose with reasonable success.

- Shield-type tip graft: Onlay shield grafts help in defining the nasal tip better, optimise the tip projection as well as provide support and hide any minor tip asymmetries.

\subsubsection{Reconstructive Grafts}

These grafts strengthen the cartilaginous framework of the nose which improves upon the existing nasal function. These grafts are placed in the sagittal plane and display long-term stability especially when an open approach is used to secure the same. They allow structural and functional reconstruction of the nasal tip in cases of definitive rhinoplasty. Examples include spreader grafts, alar batten grafts, columellar strut grafts, etc.

- Spreader graft: Spreader grafts serve to open the internal nasal valve and improve nasal breathing. Options for harvest include the septal or rib cartilages. The graft can also be made to extend more caudally making it to function like a strut for improved nasal tip support as well as to straighten and stabilise the septum. Severe septal deviation can be also corrected by placing the grafts along the dorsal septum while reattaching the caudal strut to the nasal spine between the medial crura by suture fixation.

- Alar batten graft: Batten grafts serve to strengthen the lateral crura of the LLC. The curved portion of the rib cartilage can be used to the advantage for harvesting these grafts. They are stabilised to the LLC and the strut to mimic the natural convex form of the external nasal valve and provide structural support. These grafts are critical for the correcting alar retraction whenever present.

- Columellar strut graft or septal extension graft: Such a graft provides support to the nasal base and can be a platform upon which the nasal tip can be suture stabilised. It can be harvested from the septal cartilage or from the interior of the rib cartilage.

\subsection{Treatment Strategy for Unilateral and Bilateral Cleft Nasal Deformities}

Nakamura $\mathrm{N}$ has devised a treatment strategy for both unilateral and bilateral cleft noses that addresses each anatomical and pathological abnormality that is seen in either scenarios [49]. 


\subsubsection{Unilateral Cleft Nasal Deformity}

The pathologic abnormalities that have been previously mentioned are best explained by Nakamura $\mathrm{N}$ by comparing the unilateral cleft nose to a house that is been built on a slope. The mid-pole of the house can be thought to be nasal septum, whereas the roof is the LLC and skin, the lateral pole is the vestibule and the base of the house is the maxillary bone. As the house is present on the slope, the mid-pole and the roof incline towards the downward side. In such cases, a straight house can be built on the slope by up righting the centre pole in the centre of the pillar with expansion of the lateral pole and by lifting the roof upward [49] (Fig 76.16a).

Nakamura N's treatment strategy addresses each anatomical and pathological abnormality that causes the main deformities in unilateral cleft nasal deformity listed in Table 76.1. The author's steps in definitive rhinoplasty consist of an open approach; septoplasty; repositioning of the lower lateral cartilage; medial and upward advancement of the lip and nose components, the nasal vestibular tissues, the nasal ala, nasalis muscle and the upper part of the lip including orbicular oris muscle; and nasal vestibular expansion with or without bone graft [50].

\subsubsection{Bilateral Cleft Nasal Deformity}

The pathologic abnormalities that have been previously mentioned are best explained by Nakamura $\mathrm{N}$ by likening the bilateral cleft nose to a house that is compressed by stress. In such cases, normal form of the nose can be created by extending the centre pole at the centre, advancing the roof upwards and extension of the lateral poles on each side (Fig. 76.16b). It is very critical to relieve the stress which in other words means relieving the pull on the nasal tip due to columellar skin shortage [49].

The treatment strategy devised by Nakamura $\mathrm{N}$ is based on the principle that the ideal technique of definitive rhinoplasty should minimise damage to either or both the upper and lower lip tissue. This strategy also addresses each anatomical and pathological abnormality that causes the main deformities of the bilateral cleft lip-nose as shown in Table 76.2. Therefore, the author's secondary correction involves open rhinoplasty, repositioning of the lower lateral cartilages, a caudal septal extension graft, medial and upward advancement of the lip and nose components, nasal vestibular expansion and columella lengthening using a nostril rim rotation flap, if necessary [51]. a

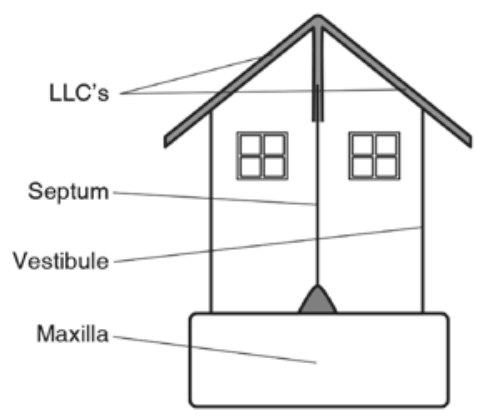

b

Normal nose

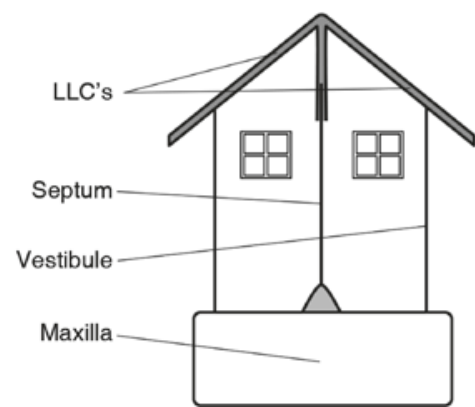

Unilateral cleft lip deformity nose

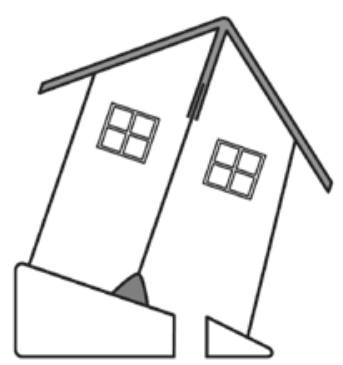

Bilateral cleft lip deformity nose

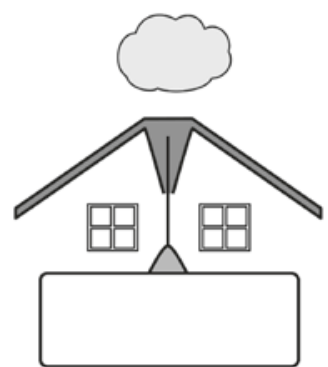

Unilateral cleft lip deformity nose correction

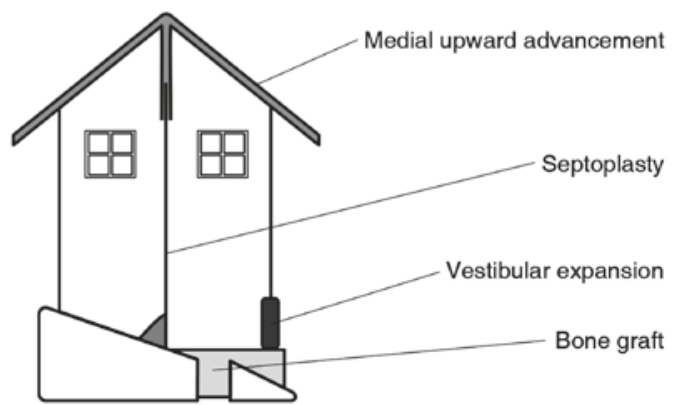

Bilateral cleft lip deformity nose correction

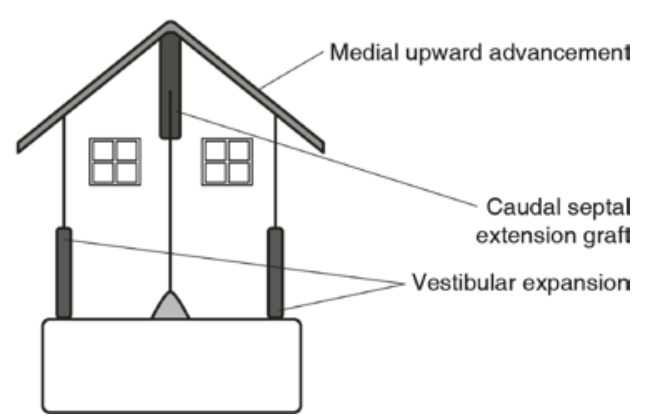

CAssociation of Oral and Maxillofacial Surgeons of India

Fig. 76.16 (a, b) Simplifying cleft nasal anatomy by Nakamura N. (a) Unilateral cleft nasal anatomy. (b) Bilateral cleft nasal anatomy 
Table 76.1 Treatment strategy for unilateral cleft nasal deformity

\begin{tabular}{|c|c|c|}
\hline $\begin{array}{l}\text { Nasal } \\
\text { deformities }\end{array}$ & $\begin{array}{l}\text { Anatomical } \\
\text { pathological } \\
\text { abnormalities }\end{array}$ & Secondary correction \\
\hline $\begin{array}{l}\text { Deviated } \\
\text { columella }\end{array}$ & $\begin{array}{l}\text { - Deviation of } \\
\text { maxillary midline } \\
\text { - Deviated septal } \\
\text { cartilage }\end{array}$ & $\begin{array}{l}\text { - Dissection around } \\
\text { anterior nasal spine } \\
\text { - Reposition of the } \\
\text { inferior base of septal } \\
\text { cartilage if necessary }\end{array}$ \\
\hline $\begin{array}{l}\text { Depressed and } \\
\text { deviated nasal } \\
\text { tip }\end{array}$ & $\begin{array}{l}\text { - Distally and } \\
\text { downwardly } \\
\text { dislocated LLC on } \\
\text { the cleft side } \\
\text { - Growth disturbances } \\
\text { of septal cartilage }\end{array}$ & $\begin{array}{l}\text { - Freeing and } \\
\text { repositioning of LLC by } \\
\text { overlapping on ULC } \\
\text { - Caudal septal extension } \\
\text { graft }\end{array}$ \\
\hline $\begin{array}{l}\text { Wide and snub } \\
\text { nasal ala on the } \\
\text { cleft side }\end{array}$ & $\begin{array}{l}\text { - Retro-positioned } \\
\text { anterior maxillary } \\
\text { wall } \\
\text { Dislocation of the } \\
\text { attachment of } \\
\text { nasalis muscle }\end{array}$ & $\begin{array}{l}\text { - Secondary bone graft if } \\
\text { necessary } \\
\text { - Supra-periosteal } \\
\text { dissection around } \\
\text { piriform margin } \\
\text { - Reposition of the nasalis } \\
\text { muscle by medial } \\
\text { upward advancement of } \\
\text { nasolabial components }\end{array}$ \\
\hline $\begin{array}{l}\text { Flat and V } \\
\text { shaped nostril }\end{array}$ & $\begin{array}{l}\text { - Webbing of the rim } \\
\text { skin } \\
\text { - Shortage of nasalis } \\
\text { vestibular lining } \\
\text { - Disconnection of } \\
\text { orbicularis oris } \\
\text { muscle }\end{array}$ & $\begin{array}{l}\text { - Bilaterally symmetric } \\
\text { reverse U incision } \\
\text { - Expansion of the nasal } \\
\text { vestibule } \\
\text { - Overlapped suturing of } \\
\text { orbicularis oris muscle }\end{array}$ \\
\hline
\end{tabular}

Nakamura N et al., J Oral Maxillofac Surg 2010; 68: 2248 [50]

\subsection{Outcomes in Cleft Rhinoplasty}

Over the past few years, there has been an increased emphasis on the functional rather than aesthetic outcomes in cleft rhinoplasty [52]. Techniques like primary cleft rhinoplasty and naso-alveolar moulding have also been laden with complications. Although several studies have compared the different techniques of rhinoplasty to determine which technique offers the best surgical outcome, these studies lack standardised objective measurements to draw any meaningful conclusions.

The data regarding functional outcomes in cleft rhinoplasty is also sparse. In one of the prospective studies with 68 cleft patients, the authors evaluated aesthetic and respiratory outcomes at two intervals, viz. pre- and 6 months postoperatively using an active anterior rhinomanometry, rhinoresistometry and acoustic rhinometry [53]. The study showed significant improvement in many parameters. The authors
Table 76.2 Treatment strategy for bilateral cleft nasal deformity

\begin{tabular}{|c|c|c|}
\hline $\begin{array}{l}\text { Nasal } \\
\text { deformities }\end{array}$ & $\begin{array}{l}\text { Anatomical } \\
\text { pathological } \\
\text { abnormalities }\end{array}$ & Secondary correction \\
\hline $\begin{array}{l}\text { Short } \\
\text { columella }\end{array}$ & $\begin{array}{l}\text { - Shortage of } \\
\text { columellar skin } \\
\text { - Tightness of } \\
\text { subcutaneous tissue } \\
\text { in the columella }\end{array}$ & $\begin{array}{l}\text { - Bilateral reverse U } \\
\text { incision } \\
\text { - Nostril rim rotation flap } \\
\text { if necessary } \\
\text { - V-Y elongation of } \\
\text { fibrous tissue }\end{array}$ \\
\hline $\begin{array}{l}\text { Flat and } \\
\text { flared nasal } \\
\text { tip }\end{array}$ & $\begin{array}{l}\text { - Growth disturbance } \\
\text { of septal cartilage } \\
\text { - Lateral and } \\
\text { downward } \\
\text { dislocation of LLC } \\
\text { - Thin skin envelope } \\
\text { of nasal tip }\end{array}$ & $\begin{array}{l}\text { - Caudal septal extension } \\
\text { graft. } \\
\text { - Freeing and reposition of } \\
\text { LLC by overlapping on } \\
\text { ULC } \\
\text { - Molding of fibrous tissue } \\
\text { on nasal tip }\end{array}$ \\
\hline $\begin{array}{l}\text { Wide and } \\
\text { snub nasal ala }\end{array}$ & $\begin{array}{l}\text { Dislocation of the } \\
\text { attachment of } \\
\text { nasalis muscle }\end{array}$ & $\begin{array}{l}\text { - Supra-periosteal } \\
\text { dissection around } \\
\text { piriform margin } \\
\text { - Reposition of the nasalis } \\
\text { muscle by medial } \\
\text { upward advancement of } \\
\text { nasal alar component }\end{array}$ \\
\hline $\begin{array}{l}\text { Flat and V } \\
\text { shaped nostril }\end{array}$ & $\begin{array}{l}\text { - Webbing of the rim } \\
\text { skin } \\
\text { - Shortage of nasalis } \\
\text { vestibular lining } \\
\text { - Disconnection of } \\
\text { orbicularis oris } \\
\text { muscle }\end{array}$ & $\begin{array}{l}\text { - Bilateral reverse U } \\
\text { incision } \\
\text { - Free mucosal graft in the } \\
\text { nasal vestibule } \\
\text { - Reposition of orbicularis } \\
\text { oris muscle }\end{array}$ \\
\hline
\end{tabular}

Nakamura N et al, J Cranio Maxillofac Surg 2011; 39: 305 [51]

concluded that while aesthetic improvement of the cleft nose is a goal, which can be achieved with regularity, nasal respiration still seems to be a challenge in cleft patients. This study highlights the need of recording functional data to study about the effects of surgery.

The outcome that is clearly documented in literature is the high satisfaction rates in patients undergoing surgery for cleft nose deformity. A study incorporating 35 patients with cleft nasal deformity was carried out by Sandor and Ylikontiola [54]. An open approach of rhinoplasty followed by alar base relocation and asymmetric nasal tip augmentation with auricular cartilage grafts was carried out in all patients. The patients' level of satisfaction was recorded in the form of a survey and interview 2 years post-surgery. A visual analogue scale (VAS) numbered 0-10 was also used by the patients to grade outcome compared to preoperative appearance at four anatomic sites. The study demonstrated highest improvements in VAS 
score for the tip, followed by alar position and dorsum and symmetry of nostrils. They noted that all patients were willing to undergo such procedure for a second time, if necessary. Two more studies have also reported high patient satisfaction rates for patients undergoing surgery for cleft nasal deformities $[55,56]$.

\subsection{Further Revisions in Cleft Rhinoplasty}

Although secondary cleft rhinoplasty is considered the ultimate revision rhinoplasty, in certain cases like those involving asymmetries or scarring, the patient's overall functional and aesthetic outcome may be compromised necessitating further revisions. It is important to remember that the principles that are followed in revision rhinoplasties are similar to those followed in primary and secondary rhinoplasties. The emphasis should be on early recognition after the definitive rhinoplasty so that revision is possible before scarring sets in.

\subsection{Complications}

The complications noted in cleft rhinoplasty are similar to those noted in the traditional open rhinoplasty in non-cleft patients. As cartilage grafts are employed, there exists a possibility of infection. Over the long term, the grafts, whether autologous, allogenous or alloplastic, can demonstrate failure. There is no difference in the risk of bleeding between cleft rhinoplasty and traditional rhinoplasty. All patients should be made aware of possible need for secondary rhinoplasty, need for revision either major or minor, existence of nostril asymmetry, visible scars, necrosis of the skin, nasal system dysfunction and morbidity associated with the donor site. One can fail to create the nasal contour as desired as well as fail in creating a normal looking appearance, and these are very common findings in cleft rhinoplasty.

\subsection{Conclusion}

Cleft rhinoplasty as a surgical procedure is often complex and complicated due to multiple surgical procedures that the patient needs over the years. Despite all the challenges that the procedure offers, the final surgical outcome could serve as a life changer for the patient in terms of aesthetics, function as well as symmetry. One should stick to the concepts of restoring symmetry and definition to the nasal tip and alar base, realigning and re-establishing the patency of nasal airway and preventing scarring and webbing from jeopardising the outcome. All cases have to be thoroughly planned preoperatively using the right assessment tools, and the surgery should be executed to near perfection. An increased emphasis should be placed on carrying out a primary rhinoplasty procedure keeping in mind that a definitive rhinoplasty will almost always be required to fine-tune the results.

\subsection{Case Scenarios}

Case 1 Figure 76.17 represents a case of right unilateral cleft nasal rhinoplasty in a 20 -year-old female managed with definitive rhinoplasty. The patient presented with the chief complaint of crooked nose and difficulty in breathing from the right nostril. The patient was subjected to thorough clinical examination of both the external and internal nasal anatomy. The following features of the cleft nose were noted: deviated nasal dorsum away from the cleft in frontal view and horizontally oriented right nostril in basal view with deviated base of columella to the left. Deviated caudal septum was also noted with difficulty in breathing in the right nostril. Concavity of the right LLC was also observed in the basal view. In the lateral view, tip ptosis was observed. The patient was subjected to open rhinoplasty approach using inverted V transcolumellar incision with incorporation of the reverse $U$ incision on the right side to correct the right nostril asymmetry. Following skeletonisation of the nose, dissection was carried between the medial crura of LLCs to expose the caudal septum which was resected to correct the septal deviation. The authors would like to stress on the importance of addressing the nasal septum almost always in all cases when performing a definitive rhinoplasty in a unilateral cleft nasal deformity. Substantial amount of septal cartilage was harvested to be used as a caudal extension graft to correct septal deviation as well as to improve tip projection. The cartilage was also utilised as an alar batten graft sutured to the lateral crura of LLC of the right side to correct the concavity of the right LLC. Bilateral spreader grafts were sutured between the ULC and the septum to improve the nasal breathing by improving the internal nasal valve function. Lateral crural steal was performed on the right side to maximise the projection of the nose, and further tip projection was achieved using 

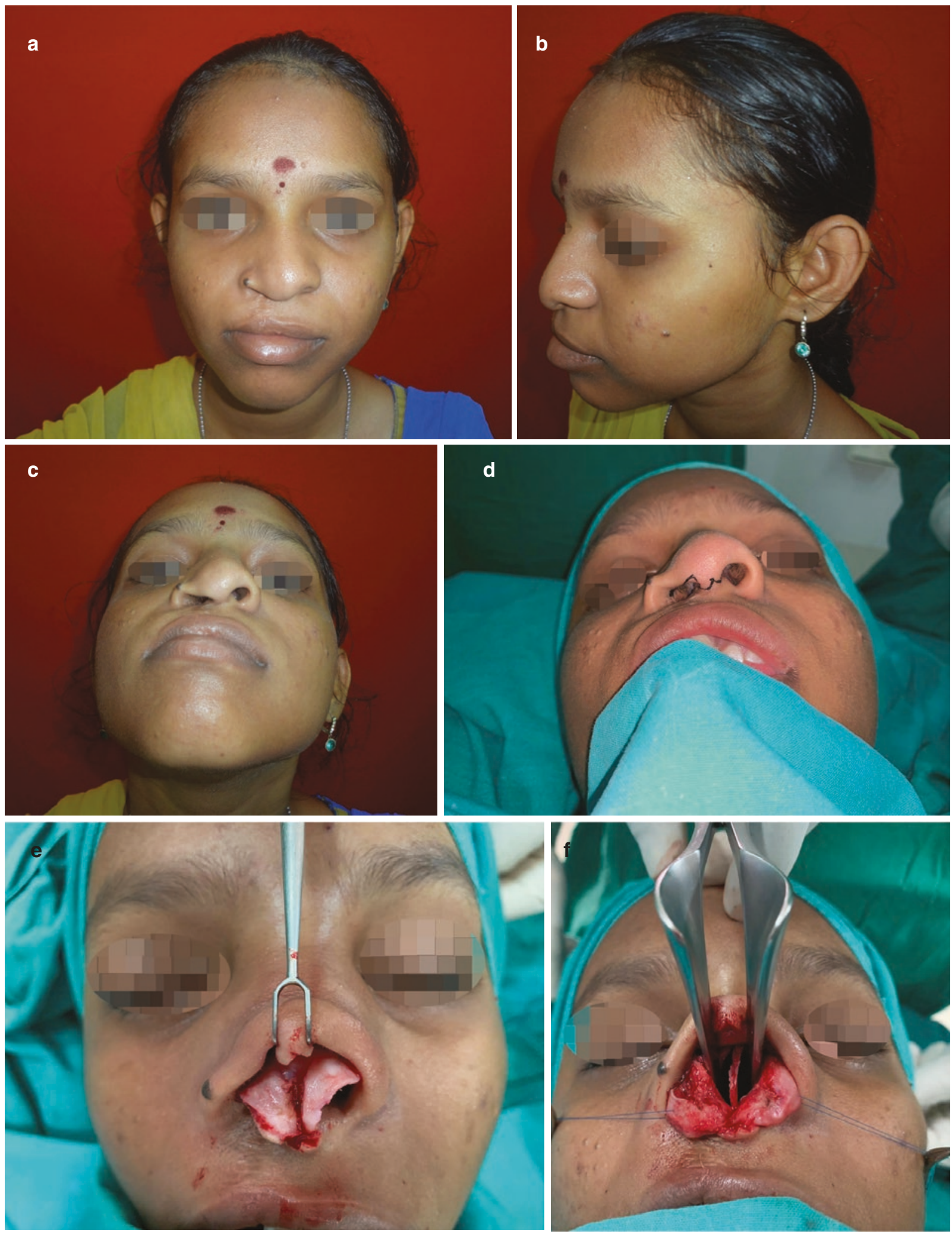

Fig. 76.17 (a-n) Clinical Scenario 1: A case of unilateral cleft nasal deformity in a 20 -year-old female managed with definitive rhinoplasty. (a) Pre op frontal. (b) Pre op lateral. (c) Pre op basal. (d) Incision marking (inverted V with Tajima modification). (e) Exposure of lower lateral cartilages. (f) Exposure of nasal septum. (g) Spreader grafts placement bilaterally. (h) Columellar strut. (i) Columellar reconstruction and alar batten graft. (j) Intra op frontal. (k) Intra op basal. (l) Post op frontal. (m) Post op lateral. (n) post op basal 

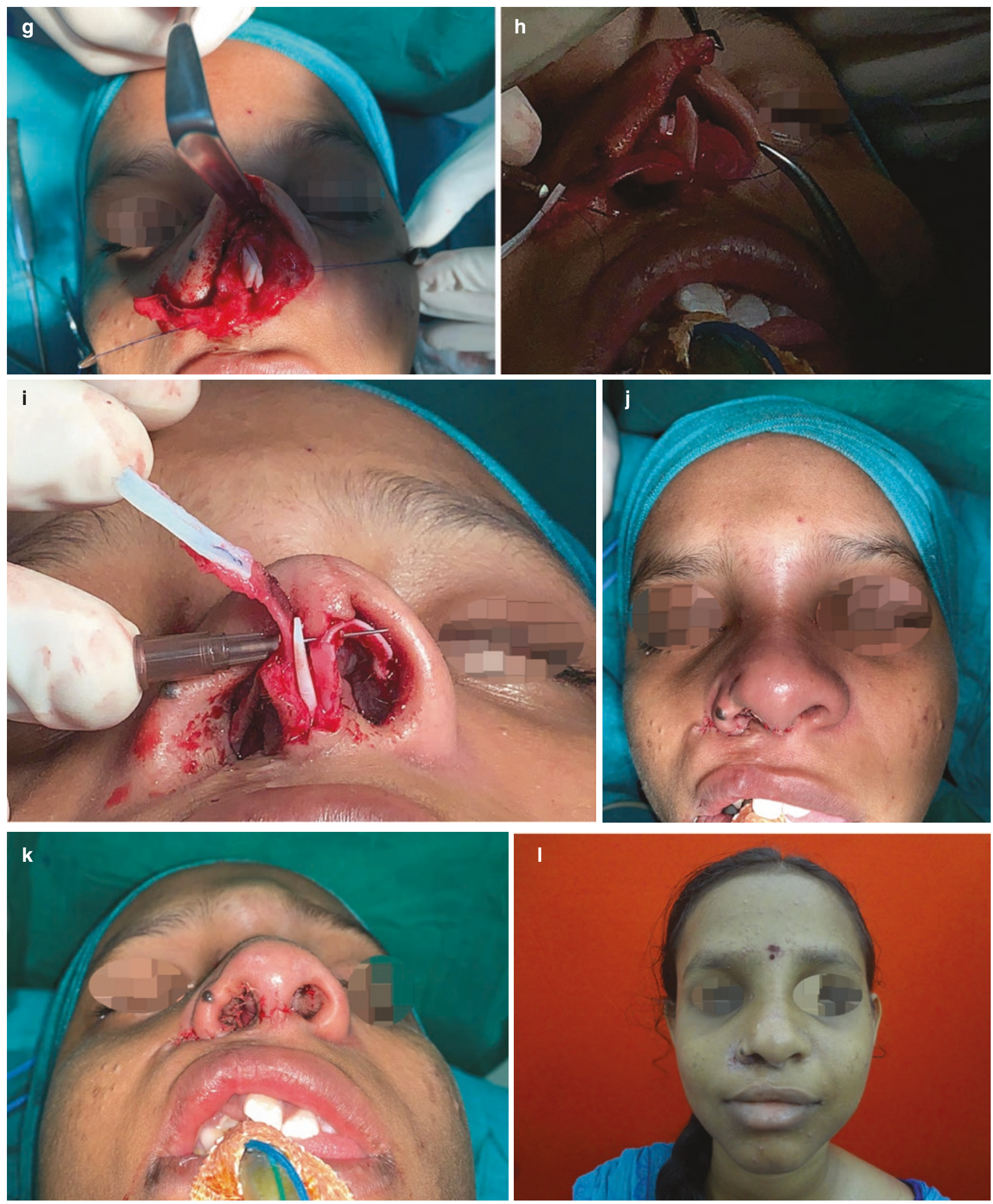

Fig. 76.17 (continued) 

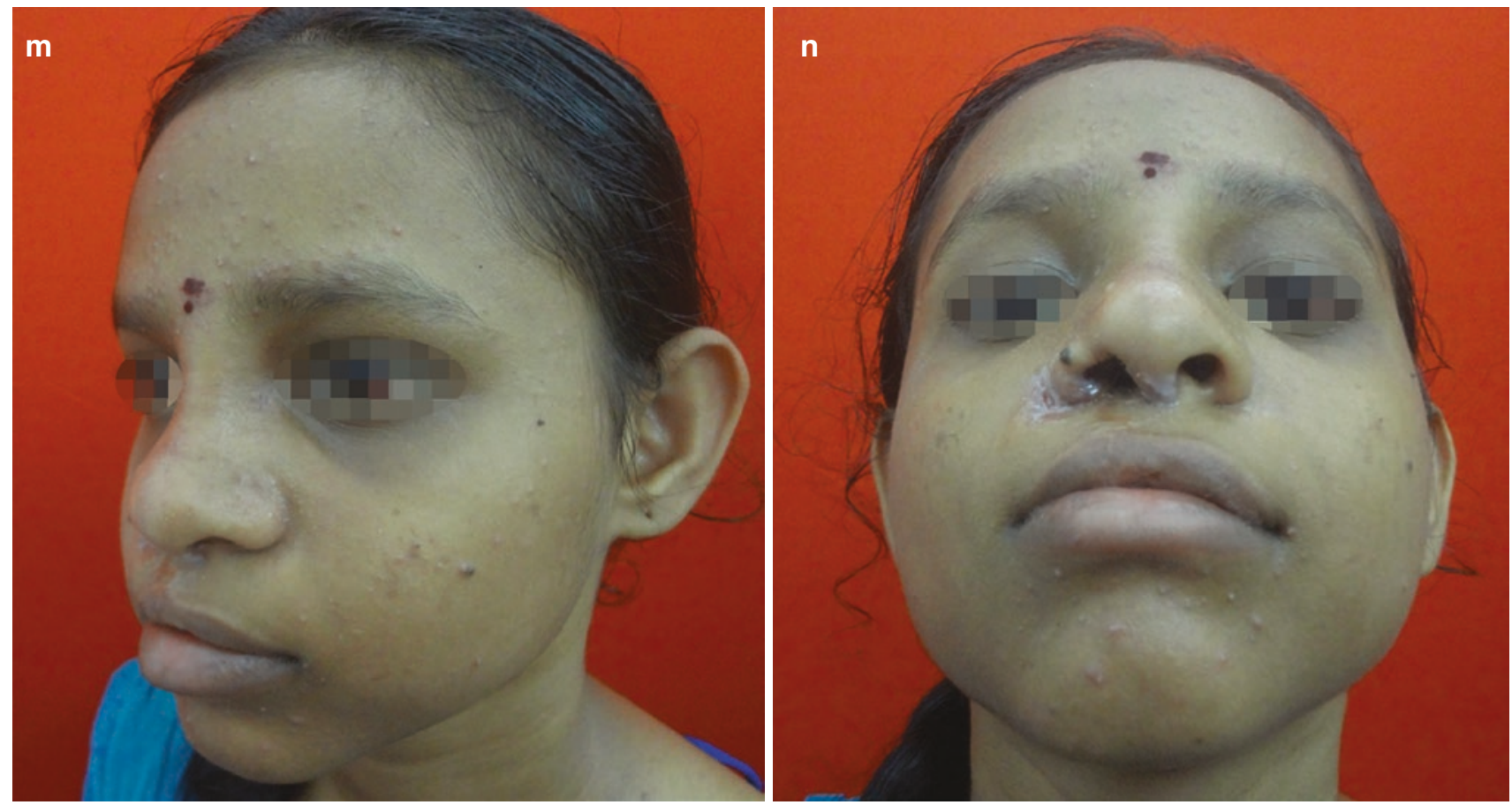

CAssociation of Oral and Maxillofacial Surgeons of India

Fig. 76.17 (continued)

interdomal sutures. The deviated nasal dorsum away from the cleft was corrected using transcutaneous lateral osteotomies bilaterally in a low to high fashion. Lastly, right alar base reduction using a Weir procedure was carried out to achieve symmetry between the two alar bases. Closure of the incision was carried out using 4-0 Vicryl Rapide sutures. Comparison of the pre- and 4 weeks postoperative photographs demonstrate significant improvement in the nasal aesthetics. The patient is very satisfied with the overall result and has no complains of difficulty in breathing.

Case 2 Figure 76.18a-k represents a case of bilateral cleft nasal deformity in a 6-year-old male managed with intermediate rhinoplasty. On clinical examination, all the features characteristic of bilateral cleft nasal deformity was evident some of which included wide dorsum with bifid nasal tip, horizontally oriented nostrils, tip ptosis and short columella with a wide base. The septum was classically midline.
Intermediate rhinoplasty was planned via an open approach in this case. An inverted V transcolumellar incision with bilateral reverse U incisions was planned to correct the horizontal orientation of the nostrils. The goal of the surgery was to primarily affect symmetric positioning of LLCs as well as to increase the length of the columella. Following exposure, dissection of the LLCs was carried out. A columellar strut from medpor was utilised which served to increase the tip projection. Symmetric positioning of LLC's was affected and sutured in place using horizontal mattress sutures. Transdomal sutures were also added to correct the bifid tip and decrease the angle of divergence between the alar domes. A modified Turkish delight graft was utilised for the purpose of dorsal nasal augmentation, and closure was affected with vicryl rapide sutures. It is important to note that any septal procedures were avoided to prevent growth disturbances. The pre- and 2 months postoperative photographs reveal a dramatic improvement and achievement of the preoperative goals. 

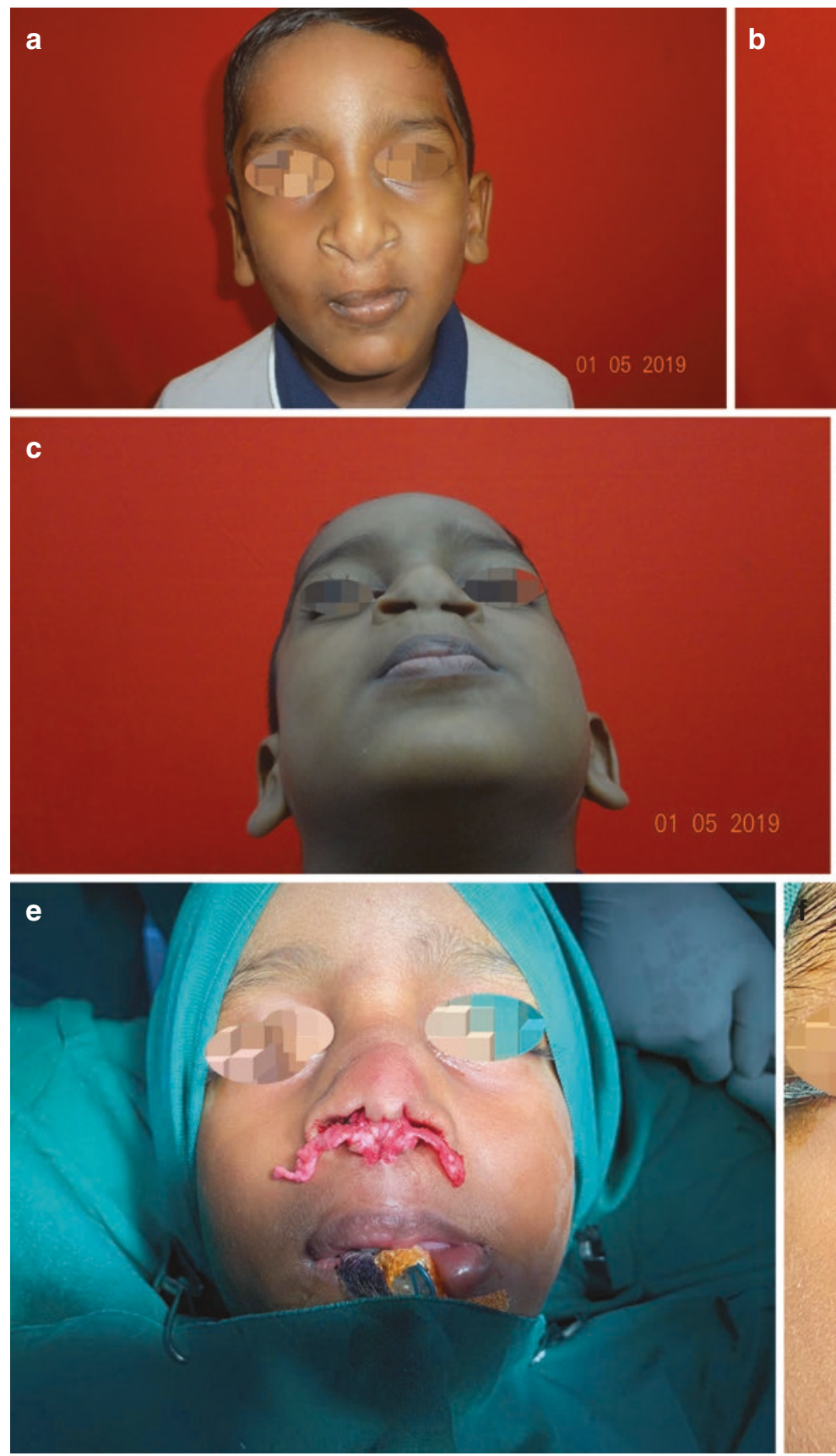
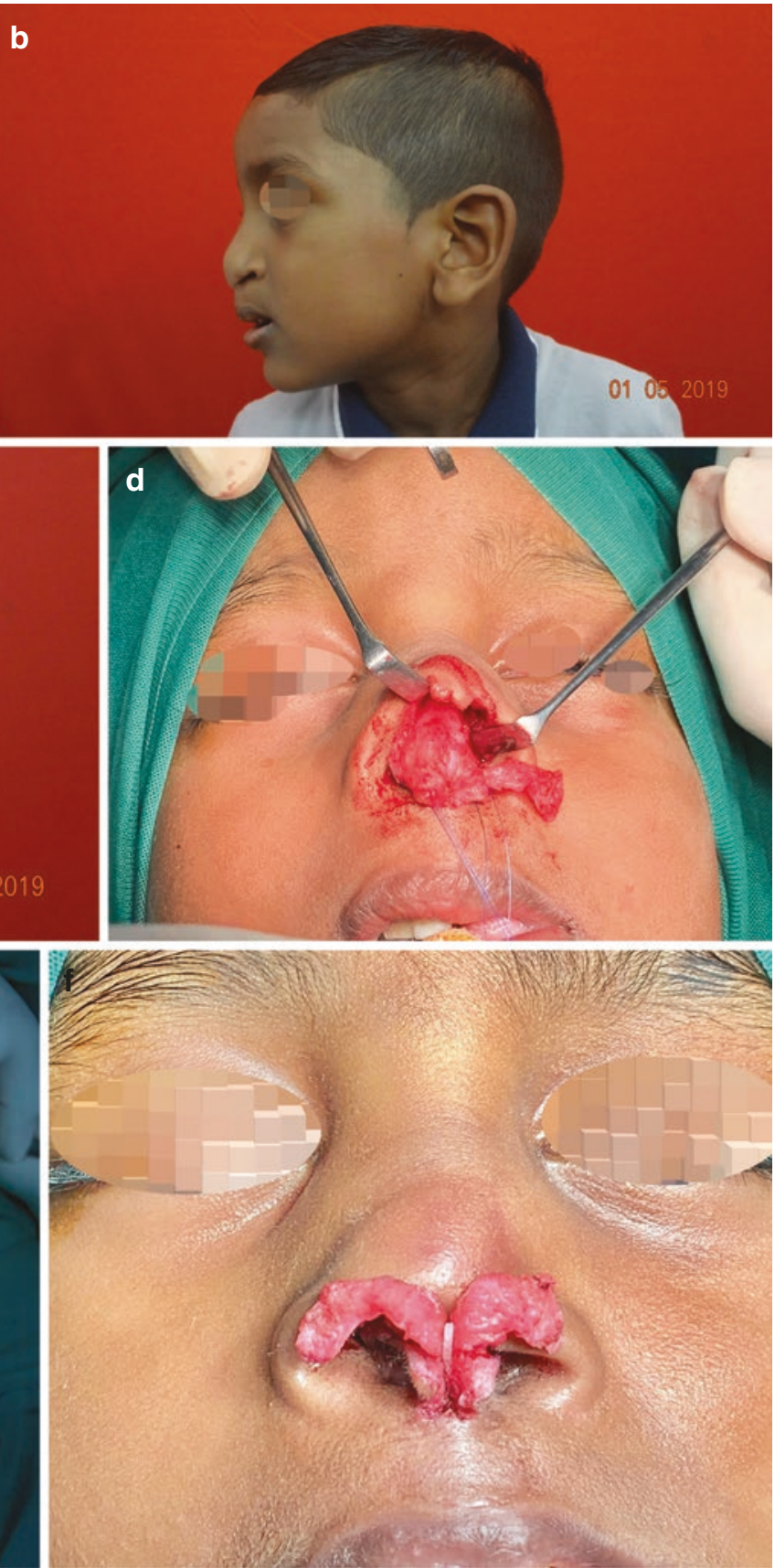

(f) Columellar strut for columellar reconstruction. (g) Modified Turkish delight for dorsal augmentation. (h) Closure. (i) Post op frontal. (j) Post op lateral. (k) Post op basal
Fig. 76.18 (a-k) Clinical Scenario 2: A case of bilateral cleft nasa deformity in a 6-year-old male managed with intermediate rhinoplasty. (a) Pre op frontal. (b) Pre op lateral. (c) Pre op basal. (d) Exposure of lower lateral cartilages. (e) Cartilage delivery after lower lateral steal. 

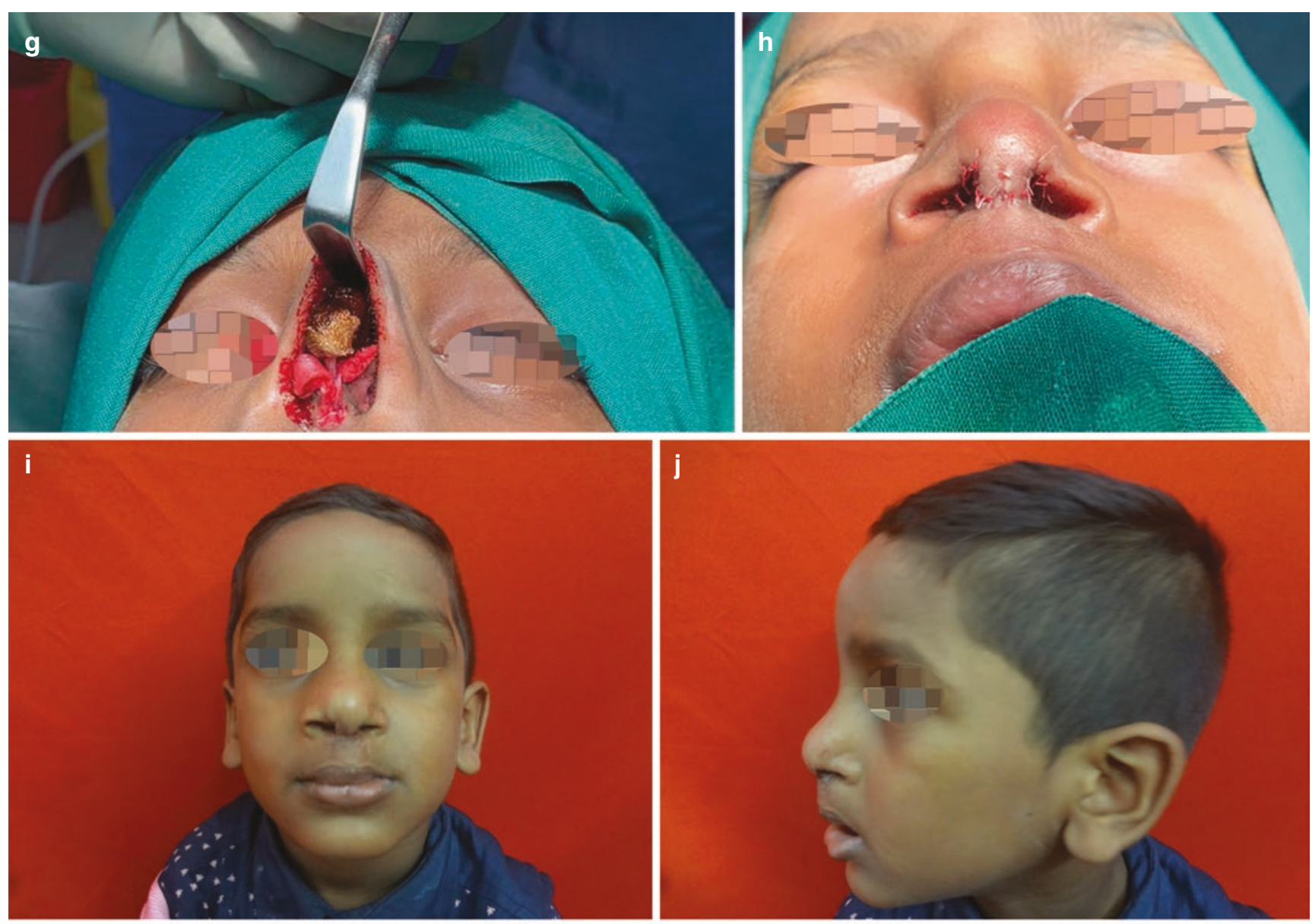

k

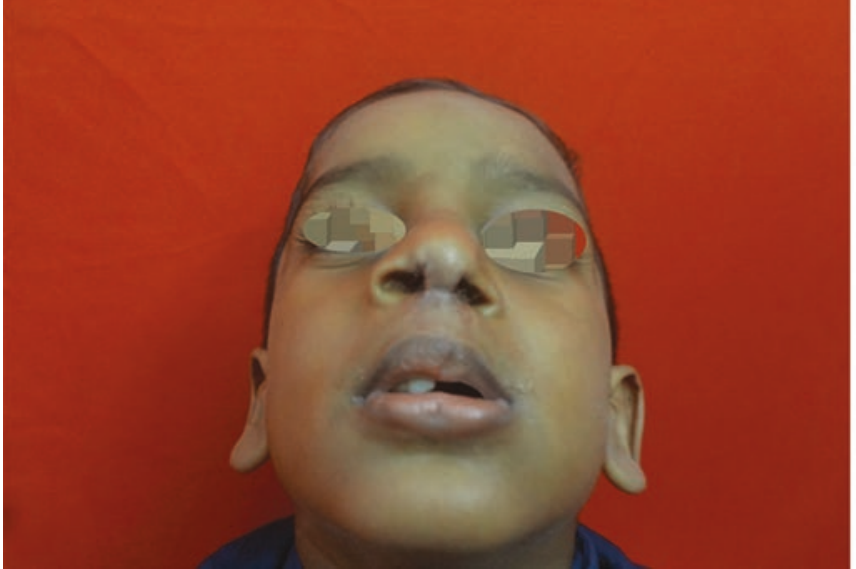

(C)Association of Oral and Maxillofacial Surgeons of India

Fig. 76.18 (continued) 


\section{References}

1. Shih CW, Sykes JM. Correction of cleft lip nasal deformity. Facial Plast Surg. 2002;18:253.

2. Bryd HS, El-Musa KA, Yazdani A. Definitive repair of the unilateral cleft lip nasal deformity. Plast Reconstr Surg. 2007;120:1348-56.

3. Fisher DM, Sommerlad BC. Cleft lip, cleft palate and velopharyngeal insufficiency. Plast Reconstr Surg. 2011;128:342e-60e.

4. Huffman WC, Lierle DM. Studies on the pathologic anatomy of the unilateral hare-lip nose. Plast Reconstr Surg. 1949;4:225-34.

5. Avery JK. The nasal capsule in cleft palate. Anat Anz. 1962;109(Suppl):722.

6. Latham RA. The pathogenesis of skeletal deformity associated with unilateral cleft lip and palate. Cleft Palate J. 1969;6:404-14.

7. McComb HK, Coghlan BA. Primary repair of the unilateral cleft lip nose. Completion of a longitudinal study. Cleft palate Craniofac J. 1996;33:23-31.

8. Bernstein L. Early submucous resection of nasal septal cartilage. A pilot study in canine pups. Arch Otolaryngol. 1973;97:272-85.

9. Sykes JM, Senders CW. Surgery of the cleft lip and nasal deformity. Oper Tech Otolaryngol Head Neck Surg. 1990;1:219-24.

10. Sykes JM, Senders CW. Surgical treatment of the unilateral cleft nasal deformity at the time of lip repair. Facial Plast Surg Clin North Am. 1995;3:69-77.

11. Fisher DM, Mann RJ. A model for the cleft lip nasal deformity. Plast Reconstr Surg. 1998;101:1448-56.

12. Penfold C, Dominguez-Gonzalez S. Bilateral cleft lip and nose repair. Br J Oral Maxillofac Surg. 2011;49:165-71.

13. Mulliken JB. Correction of the bilateral cleft lip nasal deformity. Evolution of a surgical concept. Cleft Palate Craniofac J. 1992;29:540-5.

14. Noordhoff MS. Bilateral cleft lip reconstruction. Plast Reconstr Surg. 1986;78:45-54

15. Morovic CG, Cutting C. Combining the Cutting and Mulliken methods for primary repair of the bilateral cleft lip nose. Plast Reconstr Surg. 2005;116:1613-9. Discussion 1620-2

16. Cronin TD. The bilateral cleft lip with bilateral cleft of the primary palate. In: Converse JM, editor. Reconstructive plastic surgery. Philadelphia: WB Saunders; 1964

17. Subramanian CS, et al. A modified presurgical orthopaedic (nasoalveolar molding) device in the treatment of unilateral cleft lip and palate. Eur J Dent. 2016;10:435-8.

18. Mulliken JB, Martinez-Perez D. The principle of rotation advancement for the repair of unilateral complete cleft lip and nasal deformity: Technical variations and analysis of results. Plast Reconstr Surg. 1999;104:1247-9.

19. Cronin TD. Lengthening columella by use of skin from nasal floor and alae. Plast Reconstr Surg Transplant Bull. 1958;21:417-26.

20. Wang TD. Secondary rhinoplasty in unilateral cleft nasal deformity. Facial Plast Surg. 2007;23:123-7.

21. Kaufman Y, Buchanan EP, Wolfswinkel EM, Wethers WM, Stal S. Cleft nasal deformity and rhinoplasty. Semin Plast Surg. 2012;26:184-90.

22. Garri JI, O'Leary K, Gabbay JS, et al. Improved nasal tip projection in the treatment of bilateral cleft nasal deformity. J Craniofac Surg. 2005; 16:834-9.

23. Li J, Shi B, Liu K, Zheung Q. A preliminary study of hard-soft tissue relationships among unoperated secondary unilateral cleft nose deformities. Oral Surg Oral Med Oral Pathol Oral Radiol. 2012;113:300-7.

24. Duskova M, Kristen M, Smahel Z. The anthropometric verification of corrective surgery outcome in cleft secondary deformities. J Craniofac Surg. 2006;17:447-53.
25. Trottman CA, Faraway JJ, Losken HW, van Aalst JA. Functional outcomes of cleft lip surgery: Part II: Quantification of nasolabial movement. Cleft Palate Craniofac Surg. 2007;44:607-16.

26. Morrant DG, Shaw WC. Use of standardised video recording to assess cleft surgery outcome. Cleft Palate Craniofac J. 1996;33:134-42.

27. Sykes JM, Senders JW, Wang TD, Cook TA. Use of the open approach for repair of secondary cleft lip-nasal deformities. Facial Plast Surg. 1993;1:111-26.

28. Millard DR Jr. Columella lengthening by a forked flap. Plast Reconstr Surg. 1958;22:545.

29. Nakamura N, Sasaguri M, Okawachi T, Nishihara K, Nozoe E. Secondary correction of bilateral cleft lip nose deformity. Clinical and three-dimensional observations on pre- and postoperative outcome. J Craniomaxillofac Surg. 2011;39:305-12.

30. Tajima S, Maruyama M. Reverse U incision for secondary repair of cleft lip nose. Plast Reconstr Surg. 1977;60:256-61.

31. Haddock NT, McRae MH, Cutting CB. Long term effect of primary cleft rhinoplasty on secondary cleft rhinoplasty in patients with unilateral cleft lip cleft palate. Plast Reconstr Surg. 2012;129:740-8.

32. Tajima S. Follow up results of unilateral primary cleft lip operation with special reference to primary nasal correction by the author's method. Facial Plast Surg. 1990;7:97-104.

33. Bryd HS, Salomon J. Primary correction of the unilateral cleft nasal deformity. Plast Reconstr Surg. 2000;106:1276-86.

34. Mulliken JB. Primary repair of bilateral cleft lip and nasal deformity. Plast Reconstr Surg. 2001;108:181-6.

35. Park SS. Treatment of the internal nasal valve. Facial Plast Surg. 1999;7:333-45.

36. Teymoortash A, Fasunla JA, Sazgar AA. The value of spreader grafts in rhinoplasty: A critical review. Eur Arch Otorhinolaryngol. 2012;269:1411-6.

37. Jablon H, Sykes JM. Nasal airway problems in the cleft lip population. Facial Plast Surg Clin North Am. 1999;7:391-403.

38. Crockett D, Burnstead R. Nasal airway, otologic and audiologic problems associated with cleft lip and palate. In: Bradach J, Morris HL, editors. Multidisciplinary management of cleft lip and palate. Philadelphia: WB Saunders; 1990.

39. Cuzalina A, Jung C. Rhinoplasty for the cleft lip and palate patient. Oral Maxillofac Surg Clin North Am. 2016;28:189-202.

40. Ingels KJ, Orhan KS, Van Heerbeek N. The effect of spreader grafts on nasal dorsal width in patients with nasal valve insufficiency. Arch Facial Plast Surg. 2008;10:354-6.

41. Cho BC, Choi KY, Lee JH et al. The correction of a secondary bilateral cleft lip nasal deformity using refined open rhinoplasty with reverse $\mathrm{U}$ incision, $\mathrm{V}$ plasty and selective combination with composite grafting: Long term results. Arch Plast Surg 2012; 39:190-7.

42. Guyuron B. MOC-PS(SM) CME article. Late cleft lip nasal deformity. Plast Reconstr Surg. 2008;121(4, Suppl):1-11.

43. Park BY, Lew DH, Lee YH. A comparative study of the lateral crus of alar cartilage in unilateral cleft lip nasal deformity. Plast Reconstr Surg. 1998;101:905-19.

44. Chand MS, Toriumi DM. Treatment of the external nasal valve. Fac Plast Surg. 1999;7:347-55.

45. Richardson S, Agni NA, Pasha Z. Modified Turkish delight: morselized polyethylene dorsal graft for rhinoplasty. Int J Oral Maxillofac Surg. 2011;40:979-82.

46. Yan W, Zhao ZM, Yin NB, et al. A new modified forked flap and a reverse V shaped flap for secondary correction of bilateral cleft lip nasal deformities. Chin Med J (Engl). 2011;124:3993-6.

47. Rikimaru H, Kiyokawa K, Koga N, et al. A new modified forked flap with subcutaneous pedicles for adult cases of bilateral cleft lip nasal deformity: from normalisation to aesthetic improvement. J Craniofac Surg. 2008;19:1374-80. 
48. Cheon YW, Park BY. Long term evaluation of elongating columella using conchal composite graft in bilateral secondary cleft lip and nose deformity. Plast Reconstr Surg. 2010;126:543-53.

49. Nakamura N. Surgical strategy for surgical correction of unilateral and bilateral cleft lip nose deformities. In: Brenner MJ, editor. Rhinoplasty. Croatia: In Tech; 2011.

50. Nakamura N, Okawachi T, Nishihara K, Hirahara N, Nozoe E. Surgical technique for secondary correction of unilateral cleft lip nose deformity-Clinical and three-dimensional observations of pre- and post-operative nasal forms. J Oral Maxillofac Surg. 2010;68:2248.

51. Nakamura N, Okawachi T, Nishihara K, Hirahara N, Nozoe E. Surgical technique for secondary correction of unilateral cleft lip nose deformity-Clinical and three-dimensional observations on pre- and post-operative nasal forms. J Cranio Maxillofac Surg. 2011;39:305.
52. Lee TS, Schwartz GM, Tatum SA. Rhinoplasty for cleft and hemangioma related nasal deformities. Curr Opin Otolaryngol Head Neck Surg. 2010;18:526-35.

53. Huempfner-Hierl H, Hemprich A, Hierl T. Results of prospective anthropometric and functional study about aesthetics and nasal respiration after secondary rhinoplasty in cleft lip and palate patients. J Craniofac Surg. 2009;20(Suppl 2):1863-75.

54. Sandor GK, Ylikontiola LP. Patient evaluation of outcomes of external rhinoplasty for unilateral cleft lip and palate. Int J Oral Maxillofac Surg. 2006;35:407-11.

55. Chaithanyaa N, Rai KK, Shivakumar HR, Upasi A. Evaluation of the outcome of secondary rhinoplasty in cleft lip and palate patients. J Plast Reconstr Aesthet Surg. 2011;64:27-33.

56. Pitak-Arnnop P, Hemprich A, Dhanuthai K, Pausch NC. Outcome research on secondary cleft rhinoplasty: The Leipzig experience. J Plast Reconstr Aesthet Surg. 2011;64:277-8.

Open Access This chapter is licensed under the terms of the Creative Commons Attribution 4.0 International License (http://creativecommons. org/licenses/by/4.0/), which permits use, sharing, adaptation, distribution and reproduction in any medium or format, as long as you give appropriate credit to the original author(s) and the source, provide a link to the Creative Commons license and indicate if changes were made.

The images or other third party material in this chapter are included in the chapter's Creative Commons license, unless indicated otherwise in a credit line to the material. If material is not included in the chapter's Creative Commons license and your intended use is not permitted by statutory regulation or exceeds the permitted use, you will need to obtain permission directly from the copyright holder. 